\title{
ATOMIC RESOLUTION OBSERVATIONS OF SOLUTE- ATOM SEGREGATION EFFECTS AND PHASE TRANSITIONS IN STACKING FAULTS IN DILUTE COBALT ALLOYS-I. EXPERIMENTAL RESULTS
}

\author{
R. HERSCHITZ $\dagger$ and D. N. SEIDMAN \\ Cornell University, Bard Hall, Department of Materials Science and Engineering and \\ The Materials Science Center, Ithaca, NY 14853-0121, U.S.A.
}

(Received 20 July 1983; in revised form 17 June 1984)

\begin{abstract}
Solute atom segregation effects to individual stacking faults in $\mathrm{Co}-0.96$ at $\% \mathrm{Nb}$ and $\mathrm{Co}-0.98$ at. $\% \mathrm{Fe}$ alloys have been investigated using the atom-probe field-ion micióscope. The composition of individual stacking faults has been directly measured in the range $450-575^{\circ} \mathrm{C}$. The diameter of the analyzed cylinder of alloy was $\sim 30-50 \AA$. It is shown that the solute concentration profile falls off very quickly with distance-within less than $4 \AA$-from the plane of the fault in both alloys. And it is suggested that the $\mathrm{Nb}$ and Fe segregation effects are most likely confined to the plane of the fault. Very strong solute atom segregation effects to stacking faults have been observed in both alloys. After correction for the matrix contribution to the chemical analyses, the $\mathrm{Nb}$ concentration in the stacking faults in a $\mathrm{Co}-0.96$ at.\% $\mathrm{Nb}$ alloy is greater than the bulk composition by factors of 30,12 and 7 at annealing temperatures of 450,525 and $575^{\circ} \mathrm{C}$. The corrected $\mathrm{Fe}$ concentration in the stacking faults in a Co- 0.98 at. \% $\mathrm{Fe}$ alloy is greater than the bulk composition by factors of 10,6 and 4 at the annealing temperatures 450,550 and $575^{\circ} \mathrm{C}$. Small solute-rich fluctuations, $(\sim 5-20 \AA$ dia), whose compositions differ significantly from the average fault composition, have been observed in the plane of the stacking faults at 525 and $575^{\circ} \mathrm{C}$ in the $\mathrm{Co}-0.96$ at. $\% \mathrm{Nb}$ alloy. This, in combination with the experimental observation that at $450^{\circ} \mathrm{C}$ the stacking fault composition is close to that of $\mathrm{CO}_{2} \mathrm{Nb}$, suggests that in addition to solute atom segregation we have evidence for a disorder-order transformation within the plane of the fault with decreasing temperature. Small solute-rich fluctuations ( $\sim 20 \AA$ dia) have also been observed in the Co- 0.98 at. $\%$ alloy at 550 and $575^{\circ} \mathrm{C}$.
\end{abstract}

Résumé-Nous avons étudié les effets de la ségrégation d'atomes de soluté sur des défauts d'empilement individuels dans $\mathrm{Co}-0,96$ at. $\% \mathrm{Nb}$ et $\mathrm{Co}-0,98$ at.\% Fe à l'aide de la sonde atomique d'un microscope à émission de champ. Nous avons mesuré directement la composition des défauts d'empilement individuels entre 450 et $575^{\circ} \mathrm{C}$. La diamètre du cylindre d'alliage analysé était de l'ordre de 30 à $50 \AA$. Nous montrons que le profil de concentration en soluté décroît très vite avec la distance moins de $4 \AA$-au plan du défaut dans les deux alliages. Nous pensons done que les effets de ségrégation de $\mathrm{Nb}$ et $\mathrm{Fe}$ ne se produisent que dans le plan du défaut. Nous avons observé des effets de ségrégation atomique de soluté très forts dans les deux alliages. Après correction pour la contribution de la matrice aux analyses chimiques, la concentration en $\mathrm{Nb}$ des défauts d'empilement dans un alliage $\mathrm{Co}-0,96$ at. $\% \mathrm{Nb}$ est plus grande que la concentration dans la masse d'un facteur 30,12 et 7 pour des températures de recuit de 450,525 et $575^{\circ} \mathrm{C}$. La concentration en Fe corrigée dans les défauts d'empilement d'un alliage $\mathrm{Co}_{0}-0,98$ at. $\% \mathrm{Fe}$ est supérieure à la concentration dans la masse d'un facteur 10,6 et 4 pour des températures de recuit de 450 , 550 et $575^{\prime} \mathrm{C}$. Nous avons observé de petites fluctuations riches en soluté (diamètre compris entre $s$ et $20 \AA$ ), dont la composition diffère notablement de la composition moyenne du défaut, dans le plan des défauts d'empilement à 525 et $575^{\circ} \mathrm{C}$ dans l'alliage Co-0,96 at. $\% \mathrm{Nb}$. Ajouté à l'observation expérimentale selon laquelle la composition du défaut d'empilement à $450^{\circ} \mathrm{C}$ est proche de celle de $\mathrm{CO}_{2} \mathrm{Nb}$, ceci donne à penser qu'en plus de la ségrégation d'atomes de soluté, il y a une transformation désordre-ordre dans le plan du défaut lorsqu'on abaisse la température. Nous avons également observé de petites fluctuations riches en soluté (diamètre de $1^{\prime}$ ordre de $20 \AA$ ) dans l'alliage $\mathrm{Co}-0,98$ at. $\% \mathrm{Fe}$ à 550 et $575^{\circ} \mathrm{C}$.

Zusammenfassung-Die Segregation gelöster Atome an einzelnen Stapelfehlern wurde in den Legierungen Co-0,96 At. $\%$ Nb und Co-0,98 At. $\%$ Fe mit der Atomsonde des Feldionenmikroskopes untersucht. Die Zusammensetzung der einzelnen Stapelfehler wurde direkt für den Temperaturbereich zwischen $\mathbf{4 5 0}$ und $575^{\circ} \mathrm{C}$ gemessen. Der Durchmesser des analysierten Zylinders betrug 30-50 \&. Das Konzentrationsprofil für die segregierten Atome fallt in beiden Legierungen sehr rasch mit dem Abstand von der Stapelfehlerebene ab (innerhalb von weniger als $4 \AA$ ). Es liegt nahe, daß die $\mathrm{Nb}$ - und Fe-Segregation sehr wahrscheinlich auf die Stapelfehlerebene beschränkt ist. In beiden Legierungen wurden sehr starke Segregationseffekte an Stapelfehlern beobachtet. Nach Korrektur der Matrixbeiträge zur chemischen Analyse ergibt sich, daß die Nb-Konzentration an den Stapelfehlern der Legierung $\mathrm{Co}-0,96 \mathrm{Nb}$ bei den Auslagerungstemperaturen 450,525 und $575^{\circ} \mathrm{C}$ um $30-, 12$ - und 7 -mal höher ist als der Volumenwert. Für

†Present address: R.C.A., Astroelectronic Division, Princeton, NJ 08540, U.S.A. 
das Eisen in der Legierung $\mathrm{Co}-0,98 \mathrm{Fe}$ gelten die Faktoren 10, 6 und 4 bei den Auslagerungstemperaturen 450,550 und $575^{\circ} \mathrm{C}$. Kleine, an Lösungsatomen reiche Fluktuationsbereiche ( $\sim 5$ bis $20 \AA$ Durchmesser $)$, deren Zusammensetzung sich deutlich von der mittleren Konzentration am Stapelfehler unterscheidet, wurden in der Stapelfehlerebene bei 525 und $575^{\circ} \mathrm{C}$ im $\mathrm{Co}-0,96 \mathrm{Nb}$ aufgefunden. Bei $450^{\circ} \mathrm{C}$ liegt die Zusammensetzung am Stapelfehler bei $\mathrm{Co}_{2} \mathrm{Nb}$, soda $\mathrm{B}$ wahrscheinlich auch noch ein OrdnungsEntordnungsübergang zusätzlich zur Segregation in der Stapelfehlerebene mit sinkender Temperatur auftritt. In der Legierung $\mathrm{Co}-0,98 \mathrm{Fe}$ wurden bei den Temperaturen 550 und $575^{\circ} \mathrm{C}$ ebenfalls kleine ( $\sim 20 \AA$ Durchmesser), an Lösungsatomen reiche Fluktuationsbereiche beobachtet.

\section{INTRODUCTION}

The phenomenon of interfacial segregation plays an important role in determining many physical properties of materials [1]. Equilibrium segregation of alloying elements to internal boundaries affects processes such as corrosion, hydrogen and liquid metal embrittlement and fracture behavior of materials, while solute segregation to free surfaces has a strong influence on the processes of oxidation, catalysis and wetting. Most of the studies of interfacial segregation deal either with grain boundaries or free surfaces, while very little attention has been given to solute segregation to stacking faults-commonly called Suzuki segregation $[2,3]$. Although there have been several studies to elucidate the effects of alloying elements and temperature on stacking fault energies in cobalt alloys $[4,5]$, there have been no direct measurements of the composition of stacking faults in any alloy. This is due to the fact that stacking faults are not readily accessible to analysis by the presently available conventional surface analytical tools.

In this paper we present the results of an atomprobe field-ion microscope (FIM)-hereafter called an atom probe-study of solute segregation to stacking faults in $\mathrm{Co}-0.96$ at. $\% \mathrm{Nb}$ and $\mathrm{Co}-0.98$ at. $\% \mathrm{Fe}$ alloys. The atom-probe allows us to determine the chemical identity of individual atoms with a mass $(m)$ resolution of $(\Delta m / m) \sim 1 / 200$ [6-9]. In addition, the atom-probe has a lateral atomic resoultion for composition (in the surface) of a few angstroms and therefore it is an ideal tool for studying Suzuki segregation. The depth resolution, for chemistry, is equal to the interplanar spacing of the crystallographic region analyzed.

We have determined the temperature dependence of the solute concentration in stacking faults in $\mathrm{Co}(\mathrm{Nb})$ and $\mathrm{Co}(\mathrm{Fe})$ alloys and analyzed (see Part II) the thermodynamics of segregation in the light of the observations reported in this paper. We believe that this is the first time that the composition of individual stacking faults has ever been directly measured. These measurements show that the local concentration of solute atoms is extremely high and that solute-solvent atom interactions in the plane of the stacking fault can lead to the formation of ordered phases within the fault. In particular, we show that there are strong concentration fluctuations (5-20 $\AA$ dia), whose compositions differ significantly from the average fault composition. This leads us to the sug- gestion that in addition to solute-atom segregation, we have indirect evidence for a disorder-order transformation within the plane of the stacking fault with decreasing temperature. Our preliminary results on $\mathrm{Nb}$ segregation in $\mathrm{Co}-0.96$ at. $\% \mathrm{Nb}$ alloy were reported earlier [10].

Extensive studies of both cobalt and cobalt-based alloys abound in the literature as they exhibit an allotropic phase transformation from the hexagonal close-packed (h.c.p.) to the face-centered cubic (f.c.c.) phase [11-14]. The transformation is believed to be martensitic (athermal) in character, although there is also a thermal component [12]. The similarity of the f.c.c. and h.c.p. structures is obvious as the atoms in the (111) planes of the f.c.c. structure are arranged in an hexagonal pattern just as the atoms in the (0002) planes of the h.c.p. structure. The only difference between the two phases is the way in which the close-packed layers are stacked. In an h.c.p. metalthe atoms in the second layer are positioned above one set of hollows in the first layer and the atoms in the third layer are directly above the atoms in the first layer; the stacking sequence can be denoted as $\mathrm{AB}$ ABAB, where each letter stands for a close-packed layer. Using Frank's del-nabla notation for describing any stacking sequence $[15,16]$, the normal hexagonal close-packed structure is expressed as $\Delta \nabla \Delta \nabla \Delta$. The first two atom layers of an f.c.c. metal are arranged in the same way as in the h.c.p. structure, but the atoms of the third layer are placed in the hollows of the second layer in such a way that not until the fourth layer does the stacking sequence begin anew. The f.c.c. lattice, therefore, has the stacking sequence ABCABC, or in Frank's notation by $\Delta \Delta \Delta \Delta \Delta$.

A possible explanation of the high density of stacking faults that exists in cobalt-based alloys, lies with the fact that the difference in the Gibbs free energies $(\Delta G)$ between the h.c.p. and the f.c.c. phases is very small. Kaufman [17] has calculated the enthalpy $(\Delta H)$ and the entropy $(\Delta S)$ differences between the h.c.p. and the f.c.c. phases of a number of transition metals. For most of them $\Delta H$ and $\Delta S$ have different signs which leads to an appreciable value of $\Delta G-\Delta G=\Delta H-T \Delta S$. For Co the quantities $\Delta H$ and $\Delta S$ have the same sign and thus the value of $\Delta G$ is small compared to other metals; e.g. at $450^{\circ} \mathrm{C}$ it is equal to $7.0 \times 10^{-4} \mathrm{eV}$ atom ${ }^{-1}$. Thus, the isothermal portion of the h.c.p. $\rightarrow$ f.c.c. phase transformation is extremely sluggish and it is difficult to obtain an absolutely pure h.c.p. or f.c.c. phase. 
There are three types of stacking faults in the h.c.p. structure that do not disturb first and second nearestneighbor packing. The stacking sequence for each type of fault and their corresponding Frank's notation is given below:

(i) $1 \Delta$ intrinsic- $\mathrm{ABAB} \mid \mathrm{CBC}(\Delta \nabla \Delta \Delta \nabla \Delta)$

(ii) $2 \Delta$ intrinsic- $\mathrm{ABAB} \mid \mathrm{CAC}(\Delta \nabla \Delta \Delta \Delta \nabla)$

(iii) $3 \Delta$ extrinsic-ABABCABA $(\Delta \nabla \Delta \Delta \Delta \Delta \nabla)$.

It is expected that the stacking fault energy $(\gamma) \mathrm{in}$ h.c.p. metals follows the sequence $\gamma_{1 \Delta}<\gamma_{2 \Delta}<\gamma_{3 \Delta}$ [18]. In the case of Co the stacking fault energy is in the range $15 \mathrm{erg} \mathrm{cm}^{-2}=15 \mathrm{~mJ} \mathrm{~m}^{-2}\left(5.2 \mathrm{meV}\right.$ atom $\left.{ }^{-1}\right)$ to $27 \pm 4 \mathrm{~mJ} \mathrm{~m}^{-2}\left(9.4 \mathrm{meV}\right.$ atom $\left.{ }^{-1}\right)$ [4].

Experimental observations also indicate the presence of both intrinsic and extrinsic stacking faults in Co and Co-based alloys; their relative frequency of occurrence depends on the specimen's thermal history $[12,14]$. At temperatures close to the f.c.c. $\rightleftarrows$ h.c.p. transformation the frequency of occurrence of $1 \Delta$ intrinsic stacking faults is $\sim 10$ times greater than of $2 \Delta$ intrinsic stacking faults and approximately the same as that of the $3 \Delta$ extrinsic stacking faults. It was not found possible, in the FIM images, to distinguish among the contrast effects produced by different types of stacking faults. Hence we use the term stacking fault in a global sense.

We now briefly outline the material presented in this paper. First, the experimental details, i.e. specimen preparation, heat treatment of the alloys and the parameters used during the atom-probe analyses are presented. Then we describe the principle of the experiment. In particular, the contrast effects due to stacking faults and the basic ideas involved in chemically analyzing a stacking fault by the atom probe are considered. Finally, we present in great detail the experimental results on solute atom segregation effects to stacking faults.

\section{EXPERIMENTAL}

\subsection{Specimen preparation}

Wire specimens of $\mathrm{Co}-0.96$ at. $\% \mathrm{Nb}$ and $\mathrm{Co}-0.98$ at. $\% \mathrm{Fe}$ alloys with a diameter of 0.375 and $0.254 \mathrm{~mm}$, respectively, were fabricated at the General Electric Research Laboratory (Schenectady, New York). Atomic absorption spectroscopy analysis was performed on these alloys and the nominal compositions were found to be $\mathrm{Co}-0.96$ at. $\% \mathrm{Nb}$ and $\mathrm{Co}-0.98$ at. $\% \mathrm{Fe}$, respectively. The analyses were executed in the laboratory of Professor G. H. Morrison of the Chemistry Department at Cornell University. The wire was cut into $8.0 \mathrm{~cm}$ long specimens and these were encapsulated under vacuum $\left(10^{-6}\right.$ torr), prior to annealing treatments, in quartz capsules.

Sharply-pointed FIM specimens were prepared by a two-step polishing procedure. The first step consisted of electroetching $12 \mathrm{~mm}$ long wires of the original diameter in a chromic acid: water solution $(3: 10$ by volume) at $6 \mathrm{Vac}$, until the diameter was reduced to $\sim 0.125 \mathrm{~mm}$. Typically, it took $6 \mathrm{~min}$ of etching for a $\mathrm{Co}-0.96$ at." "Nb and $4 \mathrm{~min}$ for a $\mathrm{Co}-0.98$ at. $\% \mathrm{Fe}$ alloy to reach this diameter; a stainless-steel counterelectrode was employed. Next the thinned wires were inserted in an FIM specimen holder and sharpened to a needle-like FIM tip (an initial radius of $\sim 50-100 \AA$ ) by electroetching in a freshly-made hydrochlcric acid: water solution ( $1: 10$ by volume) at room temperature at a potential of $3.2 \mathrm{Vac}-$ also employing a stainless steel counter-electrode. Normally a tip having the desired radius was obtained by dipping a $6 \mathrm{~mm}$ length of the specimen into the solution and then electroetching away $3 \mathrm{~mm}$ length of the specimen. Occasionally, certain specimens could not be polished to the desired radius by this technique. In order to overcome this problem the electroetching procedure was continued with the application of short $(\sim 0.5 \mathrm{~s})$ voltage pulses of magnitude $1.0-5.0 \mathrm{Vac}$, until a satisfactory sharpness was achieved. A good specimen had the appearance of a well-sharpened pencil when examined with an optical microscope at a magnification of $400 \times$. The initial end form of the electroetched tip was extremely rough on an atomic scale. An atomically smooth end form was obtained by a combination of $\mathrm{dc}$ and pulse field-evaporation.

\subsection{Heat treatment of $\mathrm{Co}-0.96 \mathrm{at} . \% \mathrm{Nb}$ and $\mathrm{Co}-0.98$ at. $\% \mathrm{Fe}$ alloys}

The as-received wires were in a cold-worked state and FIM images of specimens prepared from these wires exhibited an extremely high stacking fault density $\left(>10^{11} \mathrm{~cm}^{-2}\right)$; most of these stacking faults had been produced by the plastic deformation associated with the wire drawing process.

A heat treatment was developed to:

(a) produce a reasonable stacking fault density, i.e. a few faults in the $10^{-10} \mathrm{~cm}^{2}$ field-of-view; and

(b) produce an equilibrium concentration of solute atoms on each stacking fault.

The thermal treatments which achieved these goals are summarized in Table 1. At the lowest temperature the value of the root-mean-square diffusion distance $\left(\bar{x}^{2}\right)^{1 / 2}$ was equal to one-half the distance between two stacking faults. An estimate of the integrated number of jumps during a quench (Appendix A) demonstrates that an upper limit to the corresponding value of $\left(\overline{x^{2}}\right)^{1 / 2}$ is <1 $\AA$; therefore, no redistribution of solute atoms occurred during the quench. Our specimens were not in a global thermodynamic equilibrium state, as we were unable to obtain h.c.p. stacking faults in the f.c.c. matrix for the annealing times at the $T_{a}$ 's employed. That is, we studied solute atom segregation effects to stacking faults in an h.c.p. matrix. However, our diffusion calculations (Table 1) indicated that the stacking faults were probably in local thermodynamic equilibrium. The values of $\left(\overline{x^{2}}\right)^{1 / 2}$ were large enough for the stacking faults to 
have come into thermodynamic equilibrium with the volume surrounding them; i.e. with their solute reservoirst. It is important to note that the solute concentration in both alloys was below the solid solubility limit at all values of $T_{a}$ [19].

\subsection{Chemical analyses of the stacking faults}

The atom-probe FIM was used to chemically analyze the stacking faults. This technique has been described in great detail elsewhere [6-9]. The analyses were performed at a background pressure of $4 \times 10^{-10}$ torr and a specimen temperature $\left(T_{s}\right)$ of $45 \mathrm{~K}$. A pulse fraction $(f)$ of 0.15 was used for all the analyses. The quantity $f$ is the ratio of the pulse voltage $\left(V_{p}\right)$ to the standing voltage $\left(V_{\text {d.c. }}\right)$. A constant pulse frequency of $60 \mathrm{~Hz}$ was employed. The average number of ions field evaporated per pulse was 0.02 . Using these experimental conditions we were able to obtain good agreement between the nominal solute composition, and the solute concentration as determined by the atom-probe technique for both alloys [20].

\section{PRINCIPLE OF THE EXPERIMENT}

\subsection{FIM contrast effects due to stacking faults}

The first-order contrast effects expected from stacking faults in FIM images can be understood using purely geometrical considerations. A schematic diagram of the region surrounding a pole of an FIM specimen from a perfect crystal is shown in Fig. 1(a). This region conforms to a smoothly curved surface. The size of the consecutive crystal planes constituting this region is limited by this surface. The pole is characterized by a unit normal $\mathbf{n}$. For the closepacked planes only the atoms at the plane ledges protrude enough to give rise to an image, therefore the projected image of this region consists of a series of concentric circles as shown in Fig. 1(b).

A schematic diagram of an FIM specimen which contains a single stacking fault is shown in Fig. 1(c) and (d). Figure 1(c) is a section through a pole of an FIM specimen, while Fig. 1(d) shows the contrast effect expected in the FIM image due to the presence of a stacking fault. The displacement in the stacking fault plane is characterized by the shear vector $(\mathbf{R})$. The magnitude of $|\mathbf{R}|$ is the same everywhere on the surface of the stacking fault. The intersection of the stacking fault with the surface of the tip produces an atomic step. The vertical height of this step is given by the dot product of $\mathbf{R}$ and the unit normal $\mathbf{n}$ to the crystallographic plane which the stacking fault intersects.

$$
\mathbf{R} \cdot \mathbf{n}=q d_{t / K i t},
$$

tIn the calse of the Co-0.98 at.." Fe annealed at $450 \mathrm{C}$ this may not be correct.
Table 1. A summary of the annealing temperatures $\left(T_{a}\right)$, annealing times and of calculated values of the rool-mean-square diffusion distances $\left(x^{2}\right)^{1 / 2}$ for the dilute cobalt alloys

\begin{tabular}{ccc}
\hline $\begin{array}{c}\text { Annealing } \\
\text { temperature } \\
T_{a}\left({ }^{\circ} \mathrm{C}\right)\end{array}$ & $\begin{array}{c}\text { Annealing time } \\
\text { (days) }\end{array}$ & $\begin{array}{c}\text { Root-mean-square } \\
\text { diffusion distance } \\
\left(x^{2}\right)^{1 / 2}(\AA)\end{array}$ \\
\hline 575 & 2 & 530 \\
550 & 9 & 650 \\
525 & 14 & 450 \\
500 & 14 & 245 \\
450 & 21 & 80 \\
\hline
\end{tabular}

where $q=H U+K V+L W$ and $d_{H X_{i L}}$ is the interplanar distance of the plane which the stacking fault intersects; $(H K L)$ and [ $U V W]$ are the Miller indices of the plane and the direction in a three-axis hexagonal system. The index $i$ is simply the sum of the first two indices, i.e. $i=-(H+K)$. In a four-axis hexagonal system the Miller-Bravais indices for the planes ( $h k i l)$ are the same as in a three-axis system, i.e. $h=H, k=K$ and $l=L$, whereas for the directions the relationship between the two systems is given by $U=2 u+v, V=u+2 v$ and $W=w$. The various axial systems used to describe crystals with hexagonal symmetry are given by Otte and Crocker [21]. When the indices for planes and directions are specified with respect to the four-axis hexagonal system, the value of $q$ is equal to $q=(2 u+v) h+(u+2 v) k+l w$. Since $u, v$ and $w$ are not necessarily integers, the quantity $q$ need not be an integer. If the vertical height of an atomic step is equal to a non-integral value of the interplanar spacing of the plane which the stacking fault intersects, then it is readily discernible in the FIM image-the planes have a horseshoe-like appearance. The stacking fault is invisible when the

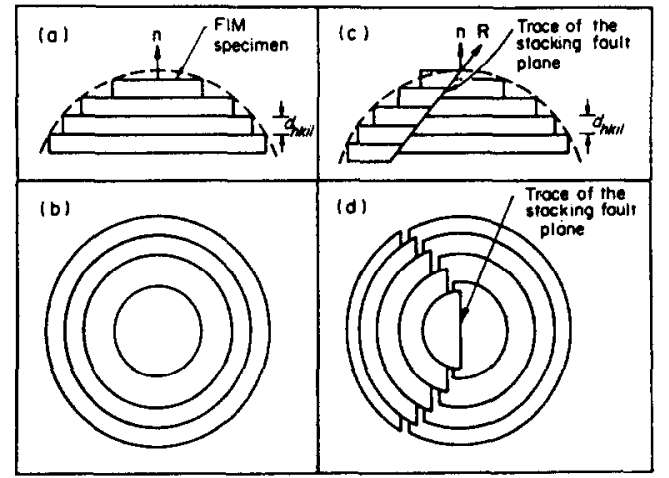

Fig. 1.(a) A cross-sectional view of a single pole on the surface of a perfect FIM tip which is characterized by a unit normal n. (b) A projected FIM image of the pole shown in Fig. 1(a). Since for close-packed planes only the atoms at the plane ledges give rise to an image, it consists of a series of concentric rings. (c) A cross-sectional view of a single pole on the surface of an FIM tip which is intersected by a stacking fault; the fault is characterized by a constant shear vector $\mathbf{R}$. An atomic step is formed on the surface as a result of the presence of the stacking fault. (d) Contrast effect produced in the FIM image by a stacking fault when it intersects the surface of the tip. Note the horse-shoe like appearance of the atomic planes. 
vertical height of a step is equal to an integral number of interplanar spacings. Consider an f.c.c. stacking fault in the h.c.p. matrix lying on an $(0002)$ plane with $\mathbf{R}=\frac{1}{3}[01 \mathrm{~T} 0]$ and intersecting the (0IT0) plane. The value of $q=\frac{2}{3}$ and, therefore, step heights of $\frac{2}{3} d_{0170}$ and $\frac{1}{3} d_{01 T 0}$ are expected during the field-evaporation dissection of a specimen. When, on the other hand, the same fault intersects the (T2T0) plane the value of $q=1$, which means that the step height is equal to $d_{1210}$. Therefore, the stacking fault should be visible in the FIM image when it intersects the (01T0) plane, but it should be invisible when it intersects the (T2T0) plane.

When the stacking fault is inclined to the tip axis its trace shifts during the field-evaporation process. Whereas when the stacking fault is perpendicular to the tip axis the trace is always a circle that is concentric with this axis.

\subsection{Atom-probe FIM analyses of stacking faults}

A schematic diagram illustrating the basic ideas involved in chemically analyzing a stacking fault by the atom probe is shown in Fig. 2(a) and (b). The stacking fault, which is parallel to the axis of the tip, is shown with a number of solute atoms residing in its plane. The specimen was rotated, employing the goniometer stage, in such a way that the center of the probe hole in the image intensification system was aligned over the stacking fault. Each atomic plane was dissected by the application of a series of fieldevaporation pulses. Typically $5 \times 10^{3}$ pulses were employed to evaporate a plane containing approx
100 atoms. The field evaporated ions which had trajectories that took them through the probe hole, in the image intensification system, were focused onto the Chevron detector with the aid of an Einzel lens. The distance of the image intensification system from the FIM tip $(\delta)$ was adjusted so that the diameter of the cylinder analyzed $\left(D_{a}\right)$ was $\sim 30-50 \AA$. The massto-charge ratios of all the atoms-both $\mathrm{Co}$ and $\mathrm{Nb}$, or $\mathrm{Co}$ and $\mathrm{Fe}$-in this cyclinder were determined by the atom-probe technique.

To obtain the composition of the analyzed cylinder of alloy the cumulative number of $\mathrm{Nb}$ or $\mathrm{Fe}$ events is plotted vs the cumulative number of either $\mathrm{Nb}$ plus Co or Fe plus Co events-such a plot is called an integral profile. The average slope of this plot corresponds to the average solute composition $\left\langle c_{s}^{\prime}\right\rangle_{u}$ of the volume analyzed, where the superscript and subscript $f$ and $s$, stand for stacking fault and solute species ( $\mathrm{Nb}$ or $\mathrm{Fe}$ ), respectively, and the subscript $u$ on the bracket means an uncorrected value. The value of $\left\langle c_{s}^{d}\right\rangle_{x}$ is a lower limit to the actual solute concentration in the stacking fault $\left\langle c_{s}^{f}\right\rangle^{*}$. The detailed relationship between $\left\langle c_{s}^{f}\right\rangle$ and $\left\langle c_{s}^{f}\right\rangle^{*}$ is discussed in the following paper [22]. In order to determine the solute composition in a region adjacent to a stacking fault plane the FIM tip was rotated in such a way that the edge of the analyzed cylinder was at a small distance $\lambda(\AA)$ away from the fault-see the schematic diagrams shown in Fig. 2(c) and (d).

The basic limitation on the value of $D_{a}$ is due to the fact that the acceptance angle of the probe hole is determined by the physical dimensions of the atom

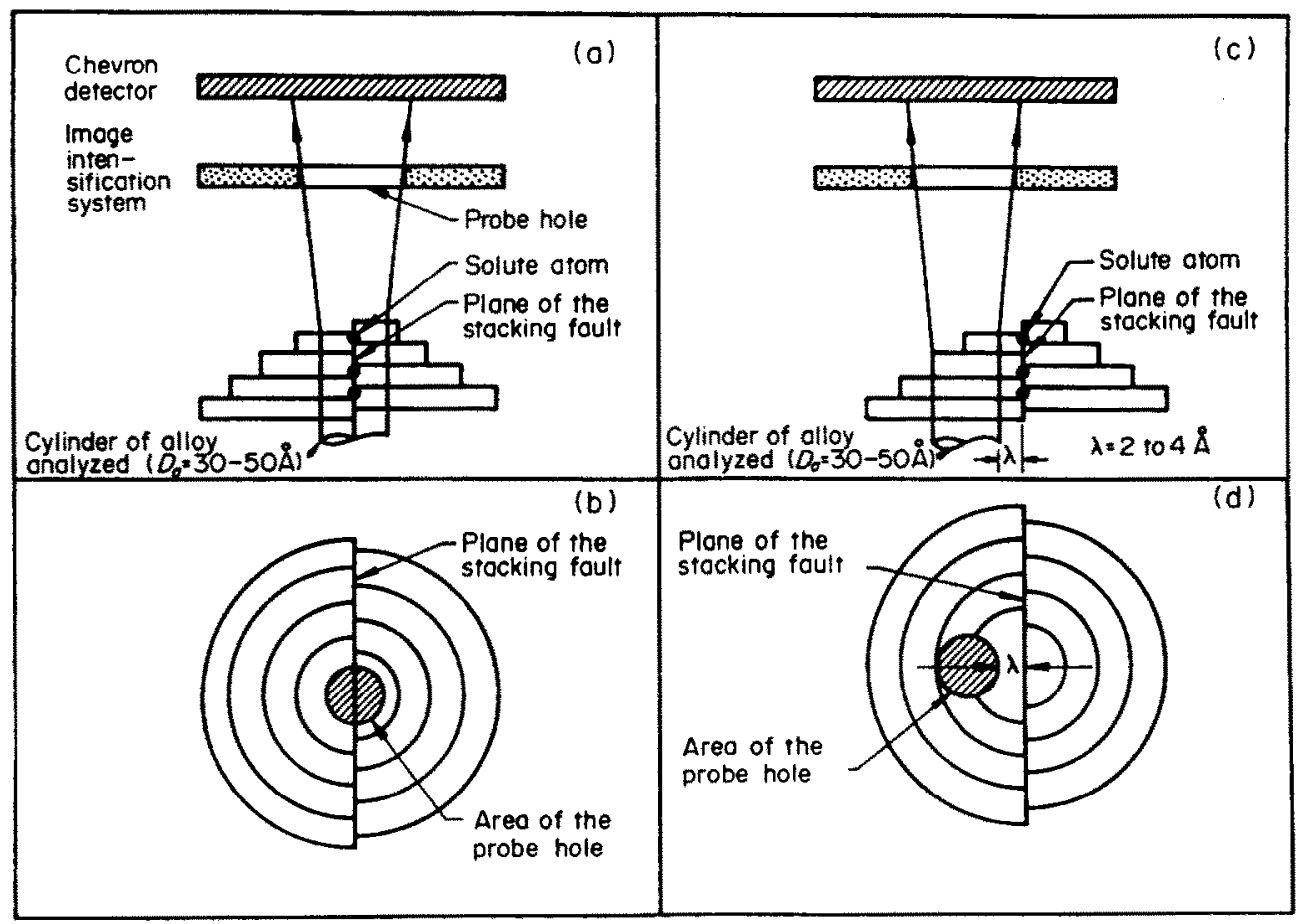

Fig. 2. (a) and (b) Schematic diagram illustrating the basic ideas involved in analyzing a stacking fault by atom-probe field-ion microscopy. (c) and (d) Schematic diagram illustrating the basic ideas involved in analyzing a cylinder of alloy which is $\lambda \AA$ away from the stacking fault. 
probe. It has been shown by Macrander et al. [23] that the number of ions detected during the atomprobe analysis is inversely proportional to $\delta^{2}$; therefore, even though $D_{a}$ is smaller at larger values of $\delta$, the statistics of the atom-by-atom dissection are poorer. The different methods employed to determine a value of $D_{a}$ are discussed in Appendix B.

\section{EXPERIMENTAL RESULTS}

\subsection{Field-ion microscopy of Co-0.96 at. $\% \mathrm{Nb}$ and $\mathrm{Co}-0.98$ at. $\% \mathrm{Fe}$ alloys}

A typical FIM image obtained from the as-received wires, which were in a cold-worked state, is shown in Fig. 3. This micrograph was recorded at the specimen temperature $\left(T_{s}\right)$ equal to $45 \mathrm{~K}$, employing neon as an imaging gas ( $4 \times 10^{-5}$ torr gauge pressure). Note that the density of stacking faults, which are identified from the stepped-ring or horseshoe contrast effect, is extremely high $\left(>10^{11} \mathrm{~cm}^{-2}\right)$ in these specimens. It is impossible to determine either the crystal structure or the orientation of the specimen from the micrograph. Because of this high stacking-fault density, the FIM tips prepared from the as-received wires often failed catastrophically prior to their being fully developed. The same imaging conditions, as the ones used for the tips prepared from the as-received wires, were employed for both the $\mathrm{Co}-0.96$ at. \% Nb and $\mathrm{Co}-0.98$ at. $\%$ Fe alloys.

While developing a thermal treatment to produce a reasonable stacking fault density-i.e. a few faults in the $10^{-10} \mathrm{~cm}^{2}$ field-of-view-we observed FIM images of various orientations of both the f.c.c. and h.c.p. phases, as well as partially transformed specimens of $\mathrm{Co}-0.96$ at. $\% \mathrm{Nb}$ and $\mathrm{Co}-0.98$ at. $\% \mathrm{Fe}$ alloys. Typical FIM images from perfect h.c.p. and f.c.c. crystals are shown in Figs 4 and 5. No stacking faults are seen in these micrographs. Figure 4 is an [0002]-oriented crystal of the h.c.p. phase of a $\mathrm{Co}-0.96$ at. $\% \mathrm{Nb}$ alloy. This specimen had been annealed at $900^{\circ} \mathrm{C}$ for 18 days and then aged at $380^{\circ} \mathrm{C}$ for 7 days. Figure 5 is a [111]-oriented crystal of the f.c.c. phase of a $\mathrm{Co}-0.96$ at. $\% \mathrm{Nb}$ alloy. This specimen had been annealed at $900^{\circ} \mathrm{C}$ for 18 days.

Figure 6 exhibits a partially transformed f.c.c. crystal of a Co-0.96 at. $\% \mathrm{Nb}$ alloy. The central portion of the micrograph contains a fully-ordered region having three-fold symmetry; while the outer region of the image appears somewhat disorderedindicating that the specimen had only partially transformed. This specimen had been annealed at $900^{\circ} \mathrm{C}$ for 7 days. The h.c.p. $\rightarrow$ f.c.c. transformation is very sluggish, even at $900^{\circ} \mathrm{C}$; this is consistent with the idea that there is a thermal component to this allotropic transformation. In the case of the Co-0.96 at.\% $\mathrm{Nb}$ alloy the reaction h.c.p. $\rightarrow$ f.c.c. occurs at $365^{\circ} \mathrm{C}$, while the reverse transformation f.c.c. $\rightarrow$ h.c.p. takes place at $255^{\circ} \mathrm{C}$ [19]. Whereas for the $\mathrm{Co}-0.98$ at." $\mathrm{Fe}$ alloy the transition temperatures are equal to $390 \mathrm{C}$

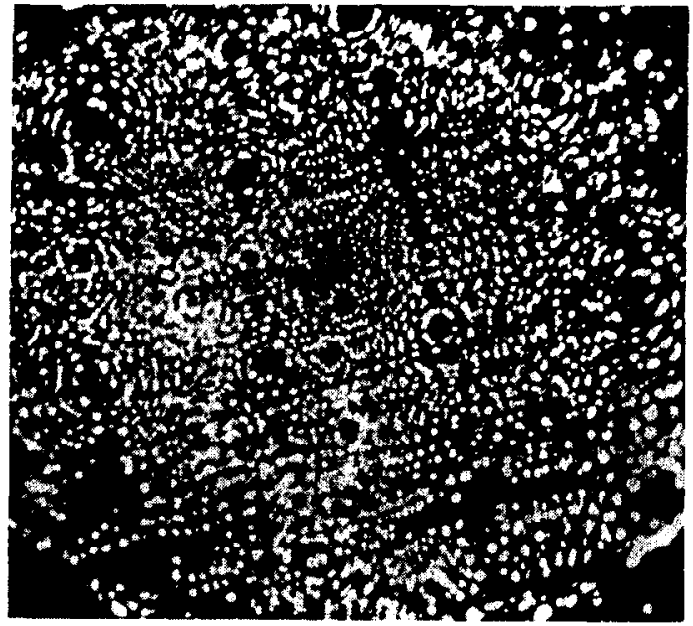

Fig. 3. An FIM micrograph of an as-received $\mathrm{Co}-0.96$ at. $\% \mathrm{Nb}$ alloy. Note that the density of stacking faults, which are identified from the stepped ring contrast effect, is extremely high $\left(>10^{11} \mathrm{~cm}^{-2}\right)$ in these specimens.

for the h.c.p. $\rightarrow$ f.c.c. transformation and $345^{\circ} \mathrm{C}$ for the f.c.c. $\rightarrow$ h.c.p. transformation [19].

Figure 7 exhibits an image of an [01T1]-oriented crystal of the h.c.p. phase of the Co- 0.96 at. $\% \mathrm{Nb}$ alloy. This specimen had been annealed at $450^{\circ} \mathrm{C}$ for 21 days. Note the presence of at least two stacking faults in the field-of-view, which are separated by a distance of about $20 \AA$. The characteristic horseshoelike contrast effect is clearly visible in the (01T0) plane. The stacking faults are f.c.c. in an h.c.p. matrix and lie on (111) planes. The plane of the fault was verified by standard crystallographic procedures.

The FIM images show no evidence of precipitation on the faults. However, there is "bright spot" decoration of some of the faults. These "bright spots" may be interpreted as niobium atoms, but stacking faults in pure cobalt also exhibit this same "bright spot" decoration effect. Therefore, it is extremely dangerous to determine chemistry based solely on the presence of "bright spots" [24]. It is interesting to note that even though the composition measured, with the atom probe, for different faults is approximately the same, we found that some faults were decorated with a large number of "bright spots" along their traces, while others were not decorated at all. This observation indicates that the mechanism for imaging solute atoms on stacking faults is a function of the crystallographic plane(s) which the fault intersects.

A field evaporation sequence through the (01T1) plane is exhibited in Fig. 8. A series of 12 FIM micrographs out of the 104 recorded during the atom-by-atom dissection of the tip is shown. A schematic diagram of the plane and the traces of the two stacking faults are given below each FIM micrograph. To simplify the understanding of the contrast 


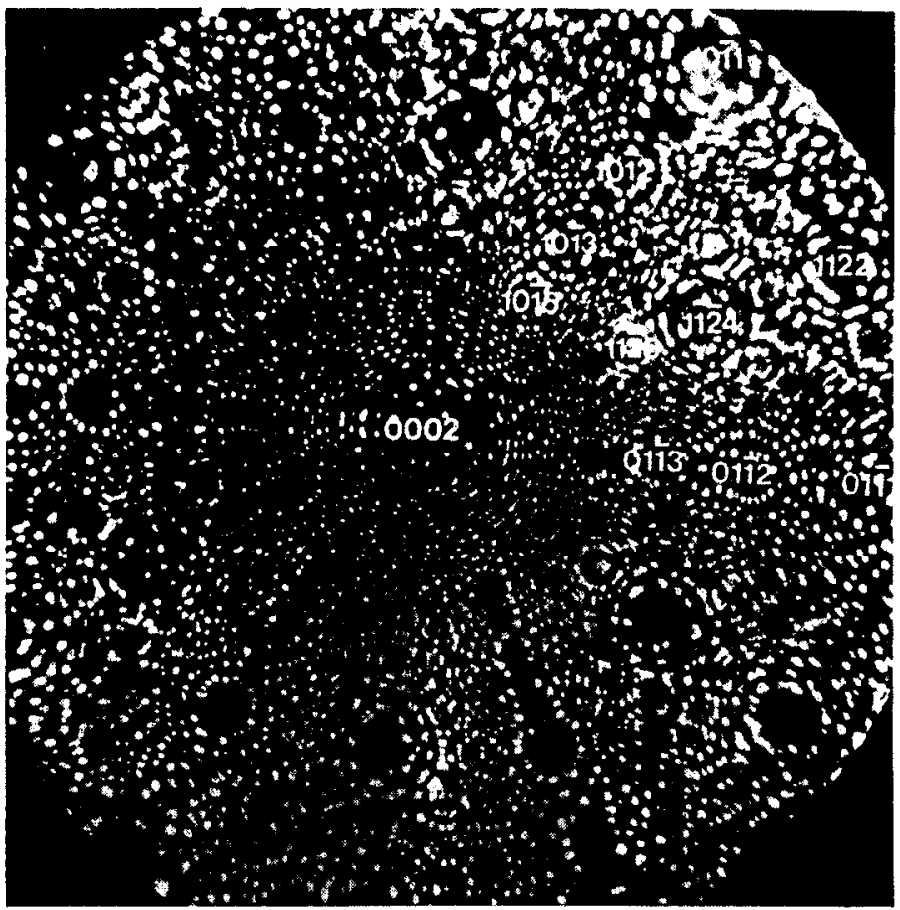

Fig. 4. An FIM micrograph of an [0002]-oriented h.c.p. crystal of a $\mathrm{Co}-0.96$ at $\% \mathrm{Nb}$ alloy. The specimen had been annealed at $T_{a}=900^{\circ} \mathrm{C}$ for 18 days and then aged at $380^{\circ} \mathrm{C}$ for 7 days. No stacking faults are present in the field-of-view.

effects produced by the two stacking faults intersecting the surface, a schematic diagram of an FIM specimen which contains the two faults is shown in Fig. 9. Figure $9(\mathrm{a})$ is a cross-section through a pole of an FIM tip, while Fig. 9(b) shows the contrast effects expected in the FIM image. The first frame in Fig. 8 shows an (01T1) plane with the diameter of the topmost ledge at its maximum size; i.e. right after the

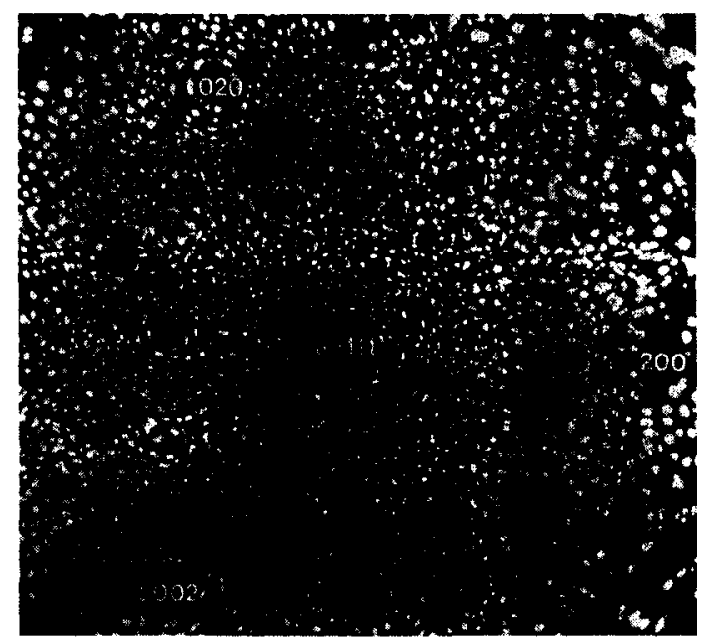

Fig. 5. An FIM micrograph of a [111]-oriented f.c.c. crystal of a $\mathrm{Co}-0.96$ at. \% $\mathrm{Nb}$ alloy. The specimen had been annealed at $T_{a}=900^{\circ} \mathrm{C}$ for 18 days. No stacking faults are present in the field-of-view preceding plane had been completely field evaporated. The planes on the bottom side of the first stacking fault trace are sheared up relative to those on the top side of the trace and sheared down relative to the planes which are on the bottom of the second stacking fault trace (Fig. 9). The process of field evaporation first removes the planes which are above the first stacking fault trace (frame 67), then it removes planes which are below the trace of the

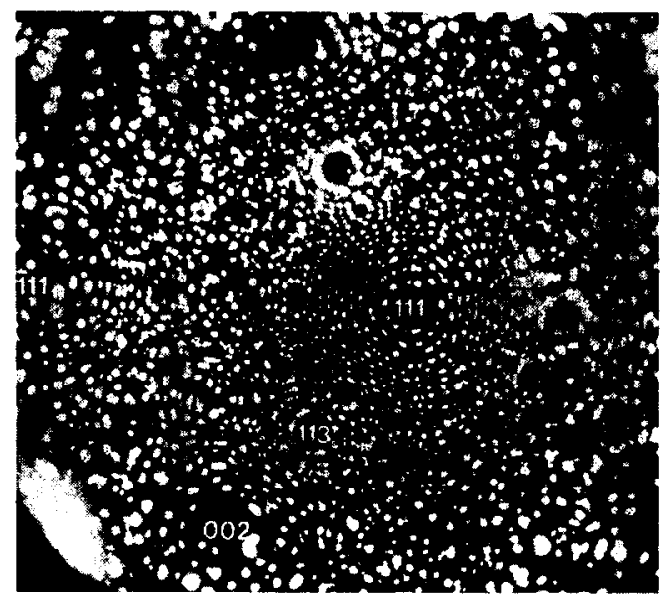

Fig. 6. An FIM micrograph of a partially-transformed f.c.c. crystal of a Co-0.96 at.\% $\mathrm{Nb}$ crystal. The specimen had been annealed at $T_{a}=900^{\circ} \mathrm{C}$ for 7 days. 


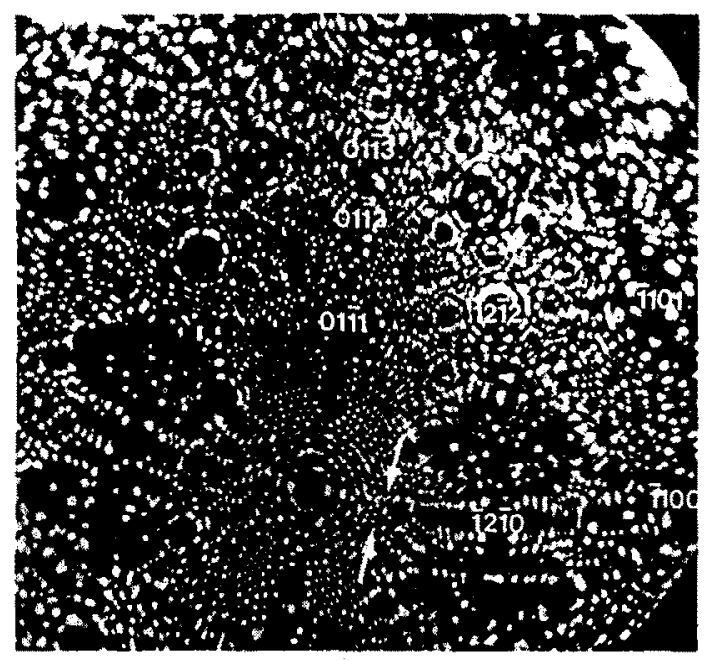

Fig. 7. An FIM micrograph of a [01T1]-oriented crystal of the h.c.p. phase of a $\mathrm{Co}-0.96$ at. $\% \mathrm{Nb}$ alloy. The specimen had been annealed at $T_{a}=450^{\circ} \mathrm{C}$ for 21 days. Arrows point to two stacking faults in the field-of view. A characteristic horseshoe-like contrast effect is clearly visible.

second stacking fault (frame 81 ), and finally it removes the planes above the trace of the first stacking fault (frame 104).
Cobalt is a non-refractory metal and, therefore, the rate at which the FIM tips failed during imaging was quite high. Very frequently, however, a phenomenon illustrated in Fig. 10 was observed in our study of cobalt-based alloys. When the FIM specimen shown in Fig. 5-a perfect r.c.c. crystal-was field-evaporated, an abrupt change in the FIM pattern occurred; in this particular case the change occurred at $V_{\text {d.c. }}$ equal to $12.5 \mathrm{kV}$. Figure 10 shows the same tip after $V_{\text {d.c. }}$ was raised to $14.4 \mathrm{kV}-$ no field-evaporation occurred during this voltage increase. Note the presence of an extremely high stacking fault density, in the field-of-view, after the abrupt change had occurred in the FIM pattern. We want to emphasize that the effect just described was very common during our study of both $\mathrm{Co}-0.96 \mathrm{at} \% \mathrm{Nb}$ and $\mathrm{Co}-0.98$ at.\% $\mathrm{Fe}$ alloys. One possible mechanism for the observed phenomenon is based on the fact that the specimens had a mixture of the f.c.c. and h.c.p. phases, and the tip may have yielded along the interphase interface under the influence of the mechanical shear stresses associated with the electric evaporation-field. The difficulty of obtaining a singlephase specimen of cobalt or cobalt-based alloys has been demonstrated by a number of experimental techniques; e.g. transmission electron microscopy
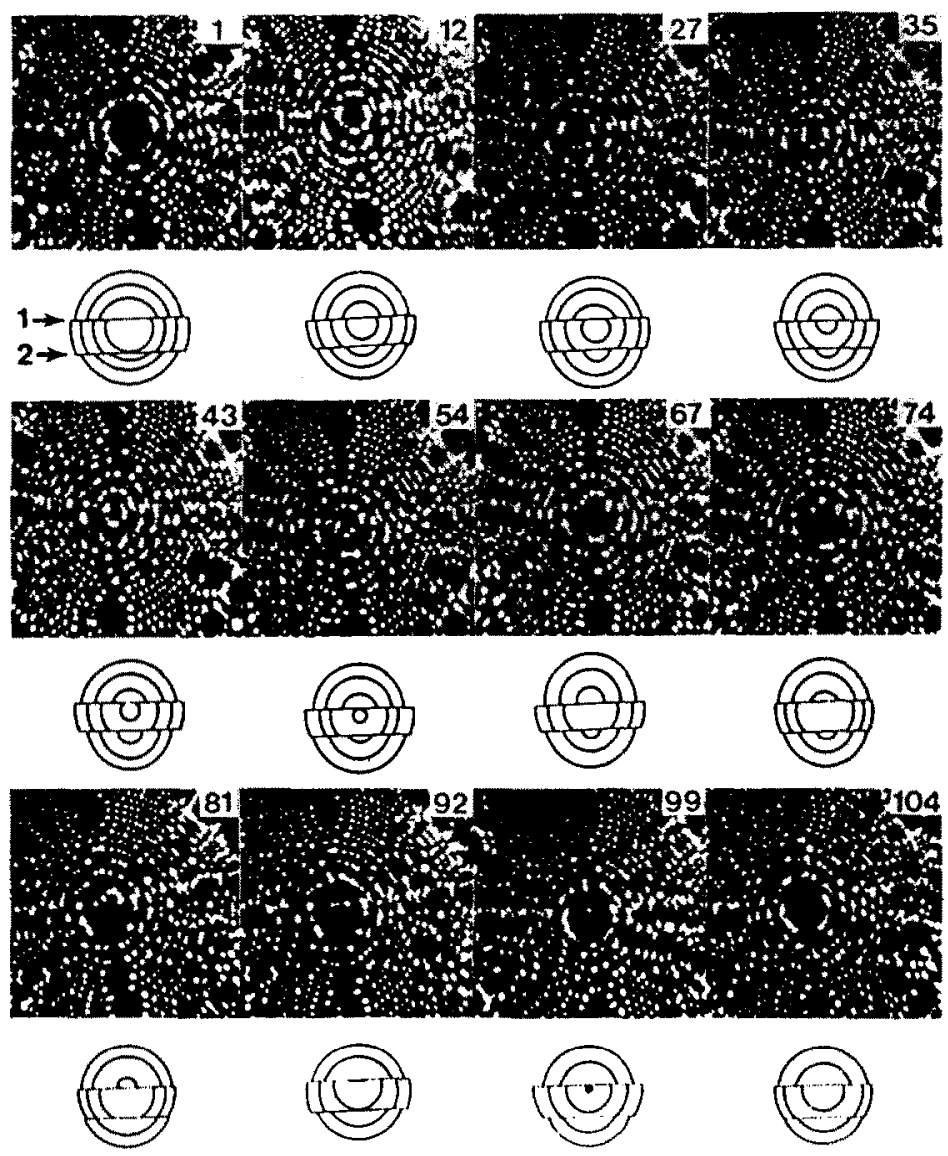

Fig. 8. A pulse fich-exporation sequence through a (01T1) plane. Twelse micrographs out of a sequence of 104 frames of cinc fim are shown. The traces due fo two stacking fauls are indicated by arrows. A schematic diagram of the situation is indicated below cach diagram. 


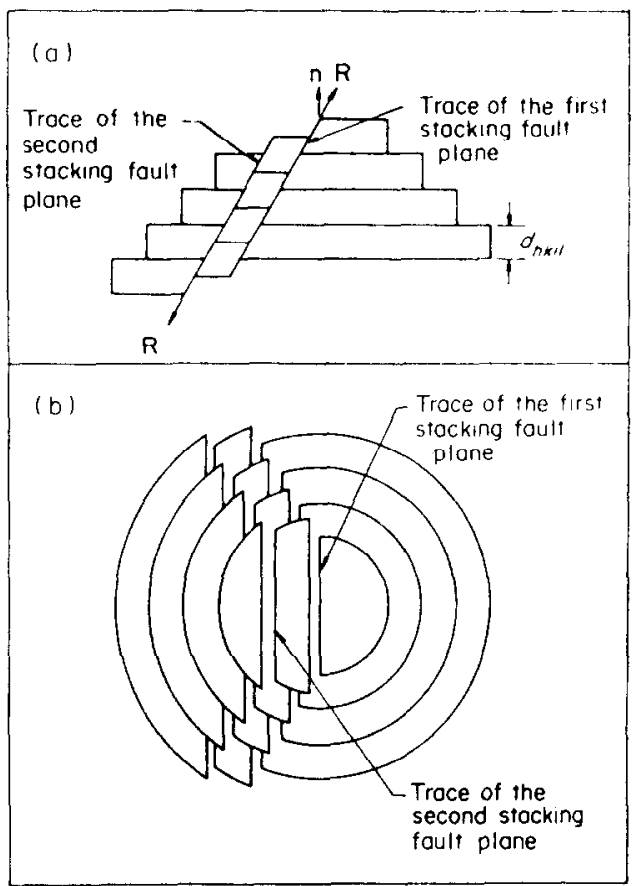

Fig. 9.(a) A cross-sectional view of a single pole on the surface of an FIM tip which is intersected by two stacking faults. (b) Contrast effect produced in the FIM image by two stacking faults when they intersect the surface of the tip.

[14], X-rays [12] and nuclear magnetic resonance [13]. The specimens almost always contained a mixture of f.c.c. and h.c.p. phases; the relative amounts were a function of $T_{a}$ and annealing time.

\subsection{Atom-probe field-ion microscopy of $\mathrm{Co}-0.96$ at. $\%$ $\mathrm{Nb}$ and $\mathrm{Co}-0.98$ at.\% Fe alloys}

Typical mass spectra-number of events vs the mass-to-charge ratio-for $\mathrm{Co}-0.96$ at. $\% \mathrm{Nb}$ and Co-0.98 at. $\% \mathrm{Fe}$ alloys have been published elsewhere $[10,20]$. We discovered during a series of detailed control experiments that the measured solute concentration is a function of both $f$ and $T_{s}$ for a fixed pulse frequency $(60 \mathrm{~Hz})$-with the average number of ions per pulse in the range $0.01-0.05$. Under certain experimental conditions quite opposite behavior was observed in these alloys-preferential field-evaporation of solute atoms in the $\mathrm{Co}-0.98$ at.\% Fe alloy and preferential retention of solute atoms in the $\mathrm{Co}-0.96$ at. $\% \mathrm{Nb}$ alloy occurred. The correct solute concentrations were obtained by using the following experimental parameters: (1) $T_{s}$ of less than or equal to $60 \mathrm{~K}$; and (2) $f$ of greater than or equal to 0.10 [20].

\subsection{Atom-probe FIM results on solute segregation to stacking faults in $\mathrm{Co}-0.96 \mathrm{at} \% \mathrm{Nb}$ and $\mathrm{Co}-0.98 \mathrm{at} . \%$ $\mathrm{Fe}$ alloys}

4.3.1. Co-0.96 at.\% Nb alloy. The $\mathrm{Nb}$ concentration in the stacking faults was measured for specimens which had been equilibrated at 450,525 and
$575($. Also the $\mathrm{Nb}$ composition in a region adjacent io stacking liatls $(i=3$ and $4 \lambda)$-see Figs $2(c)$ and (d) as well as in a region far alway $(\sim 150 \mathrm{~A})$ from the fitults wats deternined. $A$ summary of all the cisults lor the Co 0.96 att." $\mathrm{Nb}$ alloy is given in Tables 2 and 3.

The composition of the analyzed cylinder of alloy "ats determined from the slope of the integral profile. The Nh inlegral protiles atre presented in Figs $11-18$. The approximate depth scale is indicated on the top ai horizontal avis of each integral profile. The smallist vertical step corresponds to the detection of one Nh event. For a cylinder of alloy which contained a staching fault the arerage slope of the integral profile yields the value of $\left\langle c_{i n}^{\prime}\right\rangle_{n}$, whereas for a cylinder of alloy which did not contain a stacking fault the average slope gives the value of the bulk $\mathrm{Nb}$ composition $\left\langle c_{N}\right\rangle$. For specimens which had been equilibrated at $T_{1}=450 \mathrm{C}$ the values of $\left\langle c_{\mathrm{Nb}}^{\prime}\right\rangle_{\text {u }}$ for three different stacking faults (SFI. SF2 and SF3) are equal to $2.85 \pm 0.17 .3 .09 \pm 0.55$ and $3.34 \pm 0.35$ at. $\% \mathrm{Nb}-$ see Figs 11,13 and 14 . The integral profile from SF3 consists of two distinct regimes of composition $3.34 \pm 0.35$ and $1.55 \pm 0.14$ at.\% (Fig. 14). The composition in the first regime corresponds to $\left\langle c_{\mathrm{Nb}}^{\prime}\right\rangle_{u}$. The $\mathrm{Nb}$ concentration in the second regime is greater than $\left\langle c_{\mathrm{Nb}}\right\rangle$ and less than $\left\langle c_{\mathrm{Nb}}^{f_{\mathrm{u}}}\right\rangle_{\mu}$. This can be explained as follows. At the completion of the experiment it was observed that this stacking fault, although aligned over the probe hole, was not positioned over the center of the probe hole. Apparently the fault was slightly inclined to the tip axis and had shifted during the field-evaporation process. This implied that some of the atoms located in the stacking fault plane didn't have trajectories that passed through the probe hole. The values of the corrected $\mathrm{Nb}$ concentration $\left\langle c_{\mathrm{Nb}}^{\prime}\right\rangle^{*}$ for SF1, SF2 and SF3 are equal to $28.8 \pm 1.9,30.5 \pm 0.5$ and $30.6 \pm 2.1$ at. $\%$

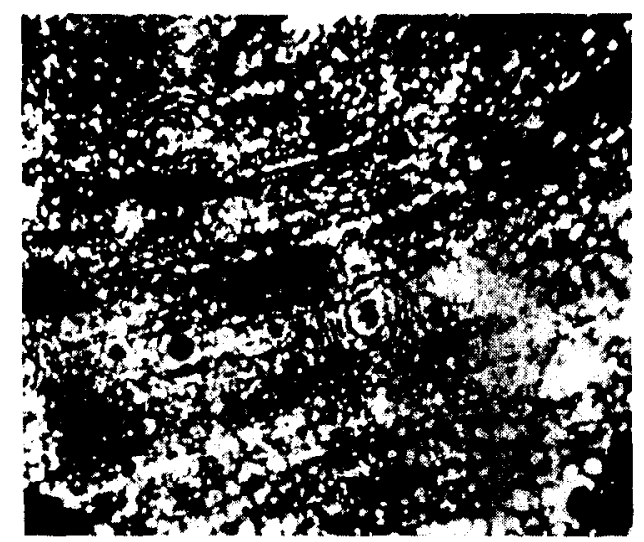

Fig. 10. An FIM image of a Co- 0.96 at. \% Nb alloy after the tip. shown in Fig. 5, had yielded under the influence of the mechanical shear stresses produced by the electric cvaporation-ficld. 
Table 2. Summary of the results on a $\mathrm{Co} .0 .96$ at." $\mathrm{Nb}$ alloy

\begin{tabular}{|c|c|c|c|c|c|c|c|}
\hline $\begin{array}{c}\text { Run } \\
\text { number }\end{array}$ & $\begin{array}{l}\text { Region } \\
\text { analyzed }\end{array}$ & $\begin{array}{c}\text { Annealing } \\
\text { temperature } \\
T_{u}(\mathrm{C})\end{array}$ & $\begin{array}{c}\text { Number } \\
\text { Co }\end{array}$ & $\begin{array}{c}\text { of atoms detected } \\
\mathrm{Nb}\end{array}$ & $\begin{array}{c}\text { Uncorrected } \\
\text { measured } \\
\text { Nb concentrationt } \\
\left\langle c_{\mathrm{Nh}}^{\prime}\right\rangle_{u} \\
\left.(\text { at. }\rangle_{0}\right)\end{array}$ & $\begin{array}{c}\text { Corrected Nb } \\
\text { concentration } \\
\langle(\mathrm{Nb}\rangle \\
(\mathrm{at} \%)\end{array}$ & $\begin{array}{c}\text { Diameter of the } \\
\text { analyzed cylindert } \\
D_{a}(\AA)\end{array}$ \\
\hline 1 & $\mathrm{SF}]$ & 450 & 9346 & 274 & $2.85 \pm 0.17$ & $28.8 \pm 7.9$ & 52 \\
\hline 2 & $\begin{array}{l}i=150 \AA \\
\text { from SFI }\end{array}$ & 450 & 1678 & 16 & $0.94 \pm 0.24$ & - & 47 \\
\hline 3 & SF2 & 450 & 1003 & 32 & $3.09 \pm 0.55$ & $30.5 \pm 0.5$ & 49 \\
\hline 4 & SF3 & 450 & 2578 & 89 & $3.34 \pm 0.35$ & $30.6 \pm 2.1$ & 44 \\
\hline 5 & SF 4 & 525 & 1161 & 20 & $1.69 \pm 0.38$ & $12.8 \pm 0.5$ & 53 \\
\hline 6 & $\begin{array}{l}\text { SF5 } \\
i=4 \AA\end{array}$ & 525 & 3224 & 57 & $1.74 \pm 0.23$ & $9.9 \pm 0.1$ & 38 \\
\hline 7 & from SF5 & 525 & 4196 & 38 & $0.90 \pm 0.15$ & - & 36 \\
\hline 8 & SF6 & 525 & 2744 & 46 & $1.65 \pm 0.24$ & $11.0 \pm 0.8$ & 51 \\
\hline 9 & SF7 & 575 & 3453 & 47 & $1.34 \pm 0.20$ & $7.3 \pm 0.2$ & $\$ 2$ \\
\hline 10 & $\begin{array}{c}i=3 \mathrm{~A} \\
\text { from } \mathrm{SF} 7\end{array}$ & 575 & 3282 & 30 & $0.91 \pm 0.17$ & . & 51 \\
\hline
\end{tabular}

The uncertainty is equal to the ratio of the square root of the number of $\mathrm{Nb}$ atoms to the total number of $\mathrm{Co}$ plus $\mathrm{Nb}$ atoms. This value of $D_{\mathrm{a}}$ is the average value calculated by the first two methods described in Appendix $B$.

Table 3. A summary of the results on the composition of solute-rich fluctuations in a $\mathrm{Co}-0.96 \mathrm{at} \% \mathrm{Nb}$ alloy

\begin{tabular}{|c|c|c|c|c|c|}
\hline \multirow{2}{*}{$\begin{array}{l}\text { Stacking } \\
\text { fault }\end{array}$} & \multirow{2}{*}{$\begin{array}{c}\text { Annealing } \\
\text { temperature } \\
T_{*}\left({ }^{\circ} \mathrm{C}\right)\end{array}$} & \multirow{2}{*}{$\begin{array}{c}\text { Uncorrected Nb concentration } \\
\text { of the fluctuation } \\
\left\langle e f\left({ }_{w b}\right\rangle_{* \text { is }}\right. \\
(\text { at. } \%)\end{array}$} & \multirow{2}{*}{$\begin{array}{l}\text { The size of the } \\
\text { fluctuation } \\
l(A)\end{array}$} & \multicolumn{2}{|c|}{$\begin{array}{c}\text { Corrected } \mathrm{Nb} \text { concentration } \\
\text { of the fluctuation } \\
\left.\left\langle\mathrm{c}_{\mathrm{Nb}}^{f}\right\rangle_{\mathrm{s}}^{*} \text { (at. } \%\right)\end{array}$} \\
\hline & & & & Lower limit $\dagger$ & Upper limit \\
\hline $\begin{array}{l}\text { SF5 } \\
\text { SF6 } \\
\text { SF7 }\end{array}$ & $\begin{array}{l}525 \\
525 \\
575\end{array}$ & $\begin{array}{l}3.43 \pm 1.40 \\
3.55 \pm 1.45 \\
3.21 \pm 1.43 \\
3.55 \pm 0.95 \\
3.20 \pm 0.72 \\
2.19 \pm 0.61 \\
2.64 \pm 0.61\end{array}$ & $\begin{array}{r}7 \\
7 \\
6 \\
13 \\
17 \\
16 \\
22\end{array}$ & $\begin{array}{l}37.5 \pm 1.4 \\
39.3 \pm 1.5 \\
34.1 \pm 1.3 \\
29.1 \pm 0.3 \\
31.1 \pm 2.2 \\
19.6 \pm 0.8 \\
26.0 \pm 1.0\end{array}$ & $\begin{array}{c}-8 \\
-8 \\
-8 \\
72.6 \pm 0.4 \\
78.0 \pm 2.5 \\
46.5 \pm 1.7 \\
50.9 \pm 2.0\end{array}$ \\
\hline
\end{tabular}

This value is calculated by taking the shape of the fluctuation to be a rectangle whose dimensions are $l \times D$.

tThis value is calculated by taking the shape of the fluctuation to be a square with dimensions $l \times l$.

In this case the values of $\left\langle c_{\mathrm{Nb}}^{f}\right\rangle_{\mathrm{i}}^{\circ}$ are greater than $100 \%$. This implies that the actual dimensions of these fluctuations are greater than $1 \times l$

$\mathrm{Nb}$, respectively. Thus at $450^{\circ} \mathrm{C}$ the stacking faults have a stoichiometry which is approximately $\mathrm{CO}_{2} \mathrm{Nb}$.

Three different stacking faults (SF4, SF5 and SF6) were also chemically analyzed in specimens which had been annealed at $T_{a}=525^{\circ} \mathrm{C}$; their corresponding $\mathrm{Nb}$ integral profiles are given in Figs 15-17. The

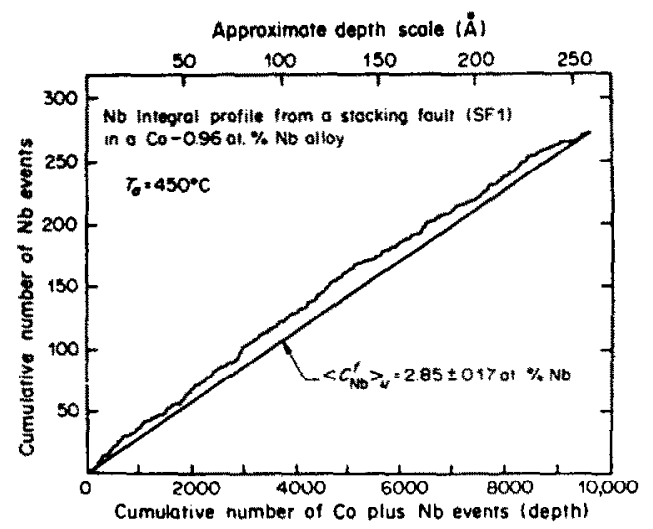

Fig. 11. The $\mathrm{Nb}$ integral protile for a cylinder of alloy which contained a stacking tault $(\mathrm{SF}):\left\langle c_{\mathrm{Nh}}^{\prime}\right\rangle_{u}=2.85 \pm 0.17$ at. ${ }_{0}$ $\mathrm{Nb}-$ this value is a lower limit to the actual $\mathrm{Nb}$ composition at a stacking fault (see $1 \times 21$ ). This speeinen had been annealed at $T_{0}=450 \mathrm{C}$ for 21 days. values of $\left\langle c_{\mathrm{Nb}}\right\rangle_{\mu}$ in this case are equal to $1.69 \pm 0.38$, $1.74 \pm 0.23$ and $1.65 \pm 0.24$ at. $\% \mathrm{Nb}$. The corresponding. values of $\left\langle c_{\mathrm{Nb}}^{\prime}\right\rangle^{*}$ are equal to $12.8 \pm 0.5$, $9.9 \pm 0.1$ and $11.0 \pm 0.8$ at. $\% \mathrm{Nb}$.

Note the presence of local solute fluctuations in some of the $\mathrm{Nb}$ integral profiles. Three such

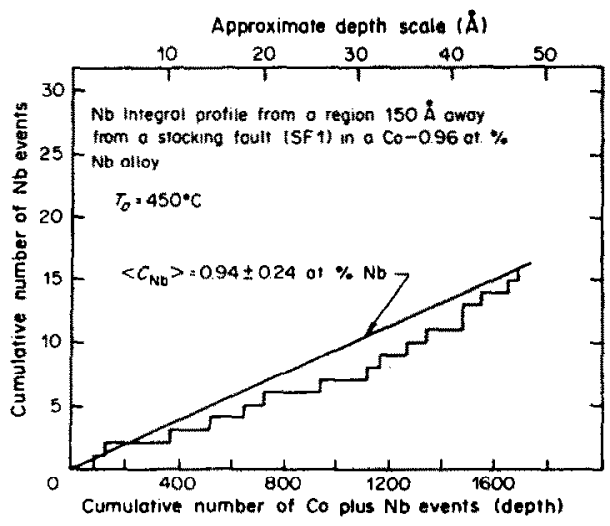

Fig. 12. The $\mathrm{Nb}$ integral protile for a region $150 \AA$ awayfrom a stacking fault $(\mathrm{SF} \mid):\left\langle c_{\mathrm{Nh}}^{t}\right\rangle=0.94 \pm 0.24$ at. $\% \mathrm{Nb}$. This value is in good agreement with the atom-probe determinations of the same quantity for specimens which did not contain any stacking fatults in the ficld-of-view. 


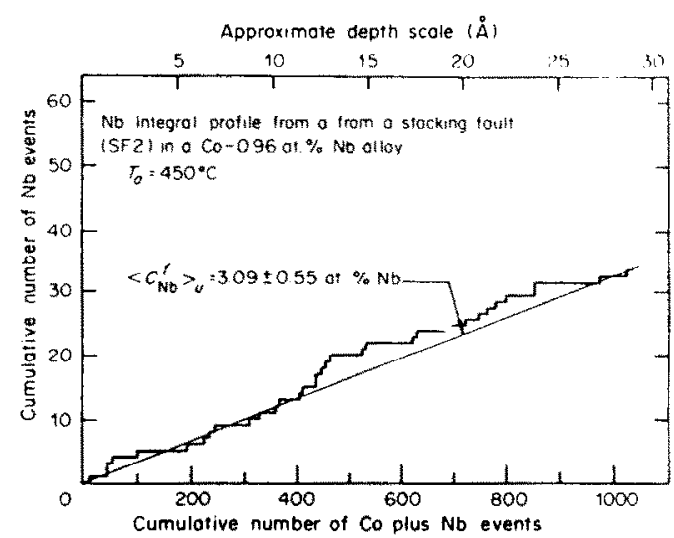

Fig. 13. The $\mathrm{Nb}$ integral profile for a cylinder of alloy which contained a stacking fault (SF2): $\left\langle c_{\mathrm{Nb}}^{\prime}\right\rangle_{u}=3.09 \pm 0.55$ at $\%$ $\mathrm{Nb}$. The specimen had been annealed at $T_{a}=450^{\circ} \mathrm{C}$ for 21 days.

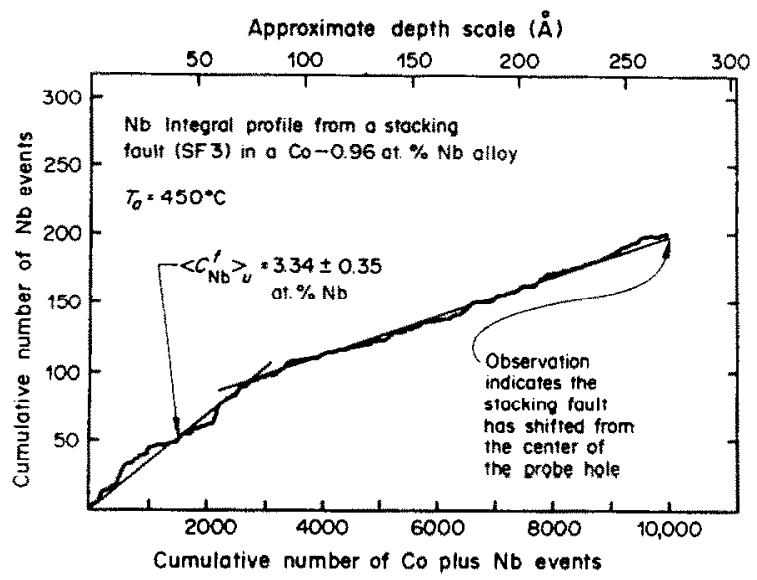

Fig. 14. The Nb integral profile for a cylinder of alloy which contained a stacking fault (SF3): $\left\langle c_{\mathrm{Nb}_{\mathrm{b}}}\right\rangle_{u}=3.34 \pm 0.35$ at. $\%$ $\mathrm{Nb}$. The specimen had been annealed at $T_{a}=450^{\circ} \mathrm{C}$ for 21 days. See text for an explanation of the two regimes.

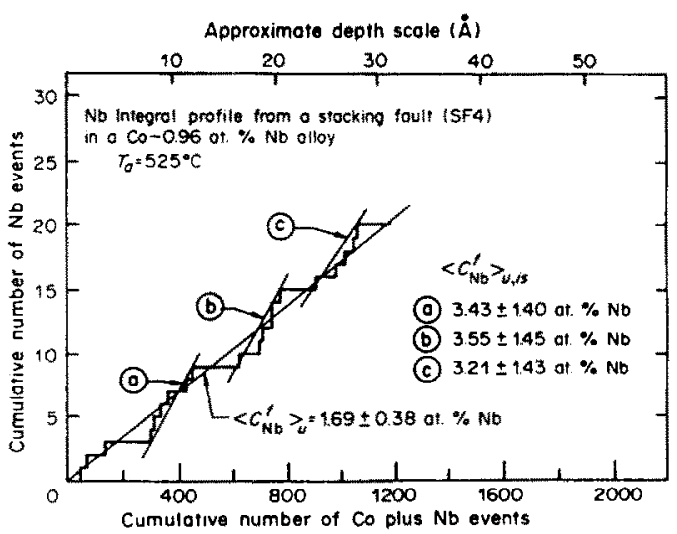

Fig. 15. The Nb integral Profile for a cylinder of alloy which contained a stacking fault (SF4): $\left\langle c_{\mathrm{Nb}}^{f}\right\rangle=1.69 \pm 0.38$ at $\%$ $\mathrm{Nb}$. Note the presence of local solute fluctuations; $\left\langle c_{N b}^{\prime}\right\rangle_{u, i s}=3.43 \pm 1.40,3.55 \pm 1.45$ and $3.21 \pm 1.43 \mathrm{at} \% \mathrm{Nb}$. This specimen had been annealed at $T_{v}=525^{\circ} \mathrm{C}$ for 14 days.

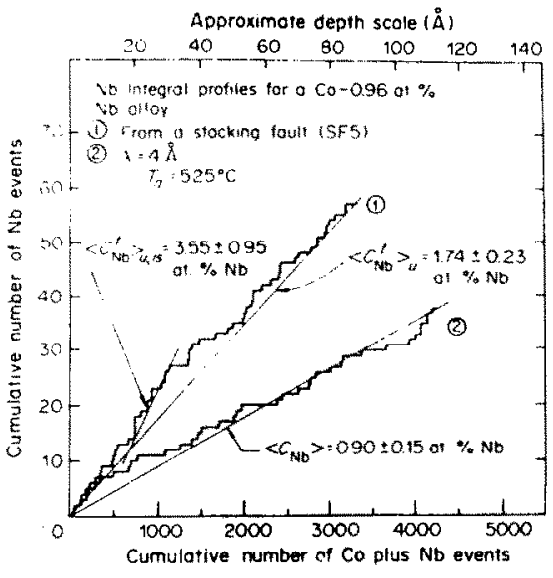

Fig. 16. The $\mathrm{Nb}$ integral profiles for: (1) a cylinder of alloy which contained a stacking fault (SF5); and (2) a region $4 \AA$ away from a stacking fault (SFS) $-\left\langle c_{\mathrm{Nb}}^{\prime}\right\rangle_{\mu}=1.74 \pm 0.23$ at. $\% \mathrm{Nb}$ and $\left\langle c_{\mathrm{Nb}}^{\prime}\right\rangle=0.90 \pm 0.15$ at. $\% \mathrm{Nb}$. Note the presence of a local solute fluctuation in $(1) ;\left\langle c_{N b}\right\rangle_{u i s}=$ $3.55 \pm 0.95$ at $\% \mathrm{Fe}$. This specimen had been annealed at $T_{u}=525$ for 14 days.

fluctuations are indicated in Fig. 15 (SF4); the values of the uncorrected $\mathrm{Nb}$ concentration in these fluctuations $\left(\left\langle c_{N b}^{f}\right\rangle_{\mu, i t}\right)$-where the subscript is on the bracket stands for a solute rich island--are equal to $3.43 \pm 1.40,3.55 \pm 1.45$ and $3.21 \pm 1.43$ at. $\% \mathrm{Nb}$. Table 3 lists all the information concerning these localized solute fluctuations. That is, their size in one dimension $(l)$ and their corrected $\mathrm{Nb}$ compositions $\left(\left\langle c_{\mathrm{Nb}}^{f}\right\rangle_{i s}^{*}\right)$. We have listed upper and lower limits to $\left\langle c_{\mathrm{Nb}}^{\prime}\right\rangle_{i s}$. The lower limit is calculated by taking the shape of the fluctuation to be a rectangle whose dimensions are $l \times D_{a}$. The upper limit is calculated by taking the shape of the fluctuation to be a square with dimensions $l \times l$.

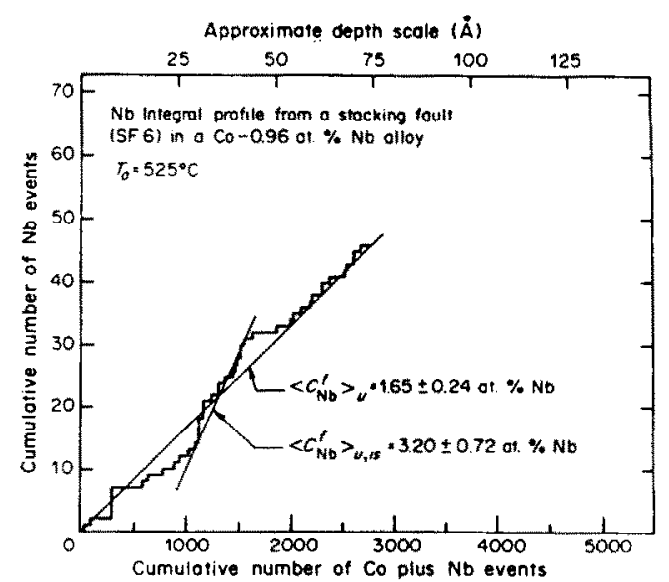

Fig. 17. The $\mathrm{Nb}$ integral profile for a cylinder of alloy which contained a stacking fault (SF6): $\left\langle c_{\mathrm{Nb}}^{f}\right\rangle_{\alpha}=1.65 \pm 0.24$ at. $\%$ $\mathrm{Nb}$. Note the presence of a local solute fluctuation; $\left\langle c_{\mathrm{Nb}}^{\prime}\right\rangle_{\text {u. }}=3.20 \pm 0.32$ at $\% \mathrm{Nb}$. The specimen had been annealed at $T_{a}=525^{\circ}$ for 14 days. 


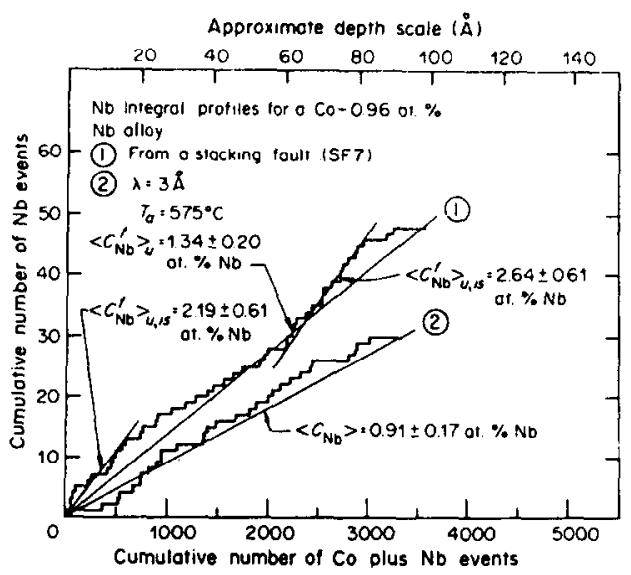

Fig. 18. The $\mathrm{Nb}$ integral profiles for: (1) a cylinder of alloy which contained a stacking fault (SF7); and (2) a region $3 \AA$ away from a stacking fault (SF7) $\left\langle c c^{f}\right\rangle_{n}=1.34 \pm 0.20$ at. $\% \mathrm{Nb}$ and $\left\langle c_{\mathrm{Nb}}^{f}\right\rangle=0.91 \pm 0.17$ at. $\% \mathrm{Nb}$. Note the presence of local solute fluctuations in (1); $\left\langle c_{N b}^{f}\right\rangle_{u, s}=2.19 \pm 0.61$ and $2.64 \pm 0.61$ at. $\% \mathrm{Nb}$. This specimen had been annealed at $T_{a}=575^{\circ} \mathrm{C}$ for 14 days.

Finally, $\left\langle c_{\mathrm{Nb}}^{f_{\mathrm{N}}}\right\rangle_{\mathrm{u}}$ for a fault (SF7) was obtained in a specimen equilibrated at $T_{a}=575^{\circ} \mathrm{C}$-it was deduced from Fig. 19 and is equal to $1.34 \pm 0.20 \mathrm{at} . \% \mathrm{Nb}$. The corresponding value of $\left\langle c_{\mathrm{Nb}}^{\prime}\right\rangle^{*}$ is equal to $7.3 \pm 0.2$ at. $\% \mathrm{Nb}$. This profile also contains local solute fluctuations whose values of $\left\langle c_{\mathrm{Nb}}^{\prime}\right\rangle_{u, \text { is }}$ are equal to $2.19 \pm 0.61$ and $2.64 \pm 0.61$ at. $\% \mathrm{Nb}$. The upper and lower limits to $\left\langle c_{\mathrm{Nb}}^{\prime}\right\rangle_{i s}$ are listed in Table 4 for SF7.

The fact that at $T_{a}=450,525$ and $575^{\circ} \mathrm{C}$ the values $\left\langle c_{\mathrm{Nb}}^{\prime}\right\rangle_{u}$ are greater than $\left\langle c_{\mathrm{Nb}}\right\rangle$ by factors of $3.0,1.7$ and 1.3 , respectively, and the value of $\left\langle c_{\mathrm{Nb}}^{f}\right\rangle^{*}$ are greater than $\left\langle c_{\mathrm{Nb}}\right\rangle$ by factors of 30,12 and 7 clearly indicates that $\mathrm{Nb}$ atoms segregate to stacking faults in a Co-0.96 at.\% Nb alloy.

For specimens annealed at $T_{a}=450^{\circ} \mathrm{C}$ the $\mathrm{Nb}$ composition in a cylinder $150 \AA$ away from the fault is equal to $0.94 \pm 0.24$ at. $\% \mathrm{Nb}$ (Fig. 13). The $\mathrm{Nb}$ concentration in a cylinder immediately adjacent to stacking faults $-\lambda=3$ or $4 \AA$-is equal to $0.91 \pm 0.17$ and $0.90 \pm 0.15$ at. $\% \mathrm{Nb}$, for specimens equilibrated at $T_{a}=575$ and $525^{\circ} \mathrm{C}$, respectively (Figs 22, 24).

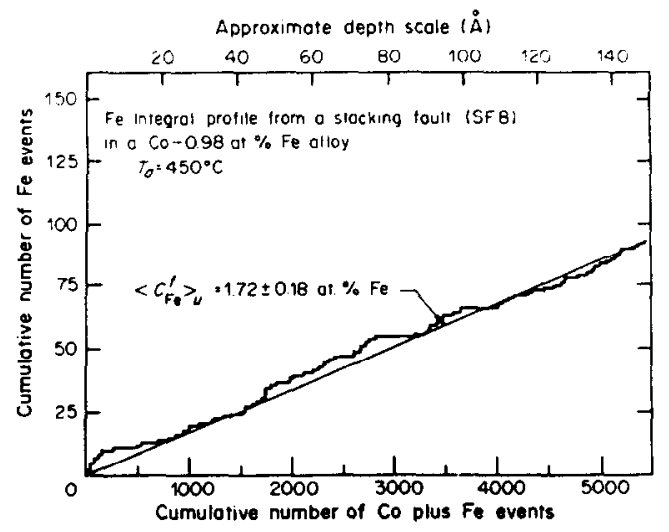

Fig. 19. The Fe integral profile for a cylinder of alloy which contained a stacking fault (SF8): $\left\langle c_{\mathrm{Fe}}^{f}\right\rangle_{\mu}=1.72 \pm 0.18$ at. $\%$ Fe. The specimen had been annealed at $T_{a}=450^{\circ} \mathrm{C}$ for 21 days.

These values of the $\mathrm{Nb}$ composition are in good agreement with $\left\langle c_{\mathrm{Nb}}\right\rangle$.

Recent theoretical calculations by Simon et al. [25] of the interaction energies between a single transition element solute atom and a stacking fault, in compact transition metals, indicate that this interaction is very short ranged-it is typically zero at two to three (111) interplanar spacings. Also, Williams and Nason [26] have shown that the surface composition of an alloy approaches the bulk composition within a few atomic planes. The experimental $\mathrm{Nb}$ concentration values for $\lambda=3$ or $4 \AA$ indicate that the $\mathrm{Nb}$ concentration profile is falling off very quickly with distancecertainly within less than $4 \AA$ from the plane of the fault the concentration is $\left\langle c_{s}\right\rangle$. These results in combination with the above theoretical calculations suggest that $\mathrm{Nb}$ segregation is most likely confined to the plane of the fault (see Part II).

The presence of local $\mathrm{Nb}$ fluctuations in the integral profiles for $T_{a}=525$ and $575^{\circ} \mathrm{C}$ (SF5, SF6, SF7) indicates the existence of small $\mathrm{Nb}$-rich regions ( $\sim 5-20 \AA$ diameter) $\dagger$ in the plane of the stacking fault whose composition differs strongly from $\left\langle c_{\mathrm{Nb}}\right\rangle^{*}$. These large $\mathrm{Nb}$ fluctuations do not exist at

Table 4. Summary of the results on a Co 0.98 at. $\%$ Fe alloy

\begin{tabular}{|c|c|c|c|c|c|c|c|}
\hline $\begin{array}{c}\text { Run } \\
\text { number }\end{array}$ & $\begin{array}{c}\text { Region } \\
\text { analyzed }\end{array}$ & $\begin{array}{c}\text { Annealing } \\
\text { temperature } \\
T_{\Delta}(\mathrm{C})\end{array}$ & $\begin{array}{c}\text { Number o } \\
\text { Co }\end{array}$ & $\begin{array}{l}\text { of atoms detected } \\
\text { Fe }\end{array}$ & $\begin{array}{c}\text { Uncorrected } \\
\text { measured } \\
\mathrm{Nb} \text { concentrationt } \\
\left\langle\mathrm{c}_{\mathrm{Fe}}^{f}\right\rangle_{\mathrm{H}} \\
\left(\mathrm{at}{ }_{0}\right)\end{array}$ & $\begin{array}{c}\text { Corrected Nb } \\
\text { concentration } \\
\left\langle c_{\mathrm{rc}}^{\prime}\right\rangle^{*} \\
(\mathrm{at} \%)\end{array}$ & $\begin{array}{l}\text { Diameter of the } \\
\text { analyzed cylindert } \\
D_{a}(A)\end{array}$ \\
\hline 1 & $\begin{array}{c}\text { SF8 } \\
i=2 \AA\end{array}$ & 450 & 5328 & 93 & $1.72 \pm 0.18$ & $9.6 \pm 0.5$ & 40 \\
\hline 2 & from SF8 & 450 & 1145 & 12 & $1.04 \pm 0.30$ & $\ldots$ & 41 \\
\hline 3 & $\begin{array}{c}\text { SF9 } \\
i=3 \AA\end{array}$ & 500 & 2955 & 4.3 & $1.43 \pm 0.22$ & $5.8 \pm 0.2$ & 33 \\
\hline 4 & from SFY & 500 & 4414 & 40 & $0.90 \pm 0.14$ & $-\ldots$ & 38 \\
\hline 5 & SF 10 & 500 & 3204 & 45 & $1.38 \pm 0.21$ & $6.9 \pm 0.2$ & 51 \\
\hline 6 & SFII & 575 & 51.55 & 64 & $1.22 \pm 0.15$ & $4.2 \pm 0.2$ & 46 \\
\hline 7 & SFI2 & 575 & 1987 & 25 & $1.24 \pm 0.25$ & $4.0 \pm 0.3$ & 39 \\
\hline
\end{tabular}

the uncertainty is equal to the ratio of the square root of the number of Fe atoms to the total number of Co plus Fe atoms.

tThis value of $D_{n}$ is the average value calculated by the first wo methods destribed in Appendix $B$. 
Table 5. A summary of the results on the compensition of solute-rich fluctuations in a (a-1).98 at.". Fe alloy

\begin{tabular}{|c|c|c|c|c|c|}
\hline $\begin{array}{l}\text { Stacking } \\
\text { fault }\end{array}$ & $\begin{array}{l}\text { Ambaling } \\
\text { emperacure } \\
T_{A}(C)\end{array}$ & 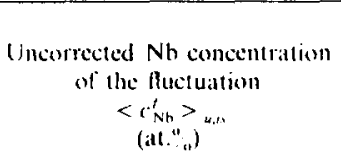 & $\begin{array}{c}\text { The sise of lak } \\
\text { hlucluation } \\
/\left(\mathcal{A}_{1}\right.\end{array}$ & \multicolumn{2}{|c|}{ 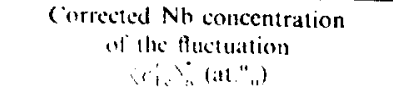 } \\
\hline SFG & 500 & $3.30 \pm 0.80$ & 14 & $22.0+1.2$ & $(.42 \pm 1.9$ \\
\hline SI:10 & $5(x)$ & $2.77 \pm 0.77$ & 14 & $23.1+1.1$ & $68.5 \pm 1.9$ \\
\hline SFII & 575 & $2.25 \pm 0.52$ & 23 & $13.7 \pm 0.9$ & $30 . x \pm 1.4$ \\
\hline
\end{tabular}

This value is catedated by laking the shape of the fluctuation to be a rectangle whose dimensions are $/$ and $D$.

tThis value is calculaled by taking the shape of the fluctuation to be a square with dimensions $/ \times l$.

$450^{\circ} \mathrm{C}$, but only become significant at the two elevated temperatures. At $450^{\prime \prime} \mathrm{C}$ the entire stacking fault has a composition which approaches that of $\mathrm{Co}, \mathrm{Nb}$. In $\lceil 22\rceil$ we also show quantitatively, using a statistical theory of fluctuations, that the probability of the occurrence of such large $\mathrm{Nb}$ fluctuations, in a random solid solution is nil. The physical origin of the $\mathrm{Nb}$-rich fluctuations is most likely the result of a disorder-order transformation-within the stacking fault-as the annealing temperature decreases.

4.3.2. Co-0.98 at. \% Fe alloy. The Fe concentration in the stacking faults was measured for specimens equilibrated at 450,500 and $575^{\circ} \mathrm{C}$. Also the $\mathrm{Fe}$ composition in a region adjacent to stacking faults $(\lambda=2$ and $3 \AA$ ) was determined. A summary of all the results for the Co.0.98 at.\% Fe alloy are given in Tables 4 and 5 .

The composition of the analyzed cylinder for this alloy was determined in the same way as for the $\mathrm{Co}-0.96$ at. $\% \mathrm{Nb}$ alloy; i.e. from the slope of each $\mathrm{Fe}$ integral profile. The results are shown in Figs 19-25. For a specimen which had been annealed at $T_{a}=450^{\circ} \mathrm{C}$ the value of $\left\langle c_{\mathrm{Fe}}^{\prime}\right\rangle_{\nu}$ from SF8 is equal to $1.72 \pm 0.18$ at. $\% \mathrm{Fe}$ (Fig. 19). The corresponding value of $\left\langle c_{\mathrm{Fe}}^{f}\right\rangle^{*}$ is equal to $9.6 \pm 0.5$ at. $\%$ Fe. Figure 20 shows an integral profile for a cylinder immediately adjacent to SF8 $(\lambda=2 \AA)$; the value of $1.04 \pm 0.30$ at. $\% \mathrm{Fe}$ is in good agreement with $\left\langle c_{\mathrm{Fe}}\right\rangle$.

Two stacking faults (SF9 and SF10) were analyzed in specimens which had been equilibrated at $T_{a}=500^{\circ} \mathrm{C}$; the values of $\left\langle c_{\mathrm{Fe}}^{f}\right\rangle_{\mu}$ in this case were deduced from the integral profiles shown in Figs 21 and 22 and are equal to $1.43 \pm 0.22$ and $1.38 \pm 0.21$ at. $\% \mathrm{Fe}$. The corresponding values of $\left\langle c_{\mathrm{Fe}}^{f}\right\rangle *$ are equal to $5.8 \pm 0.2$ and $6.9 \pm 0.2$ at. $\% \mathrm{Fe}$. The $\mathrm{Fe}$ composition for a cylinder immediately adjacent to SF9 is equal to $0.90 \pm 0.14$ at. $\% \mathrm{Fe}$; this value is in good agreement with $\left\langle c_{\mathrm{Fe}}\right\rangle$. The integral profiles from SF9 and SF10 show the presence of local solute fiuctuations; see Table 5 for details.

Finally, for specimens which had been annealed at $T_{a}=575^{\circ} \mathrm{C}$ the values of $\left\langle c_{\mathrm{Fe}}^{\prime}\right\rangle_{u}$ for two different stacking faults (SF11 and SFI2) are equal to $1.22 \pm 0.15$ and $1.24 \pm 0.25$ at. \% Fe (Figs 23 and 26).

†Note that the depth scale is given on the top axis in Figs 11-14.
The corresponding values of $\left\langle c^{\prime}\right\rangle^{*}$ are equal to $4.2 \pm 0.2$ and $4.0 \pm 0.3$ at." "Fe. The integral profile from SF11 (Fig. 23) has three local solute fluctuations whose values of $\left\langle\left\langle{ }^{\prime}\right\rangle_{\text {u.i }}\right.$ are equal to $2.23 \pm 0.56$, $2.05 \pm 0.68$ and $2.25 \pm 0.52$ at." "Fe; see Table 5 for futher details.

The fact that at $T_{a}-450,500$ and $575^{\circ} \mathrm{C}$ the value of $\left\langle c^{\prime}{ }_{\mathrm{Fe}}\right\rangle_{u}$ is greater than $\left\langle c_{\mathrm{Nh}}\right\rangle$ by factors of $1.7,1.4$

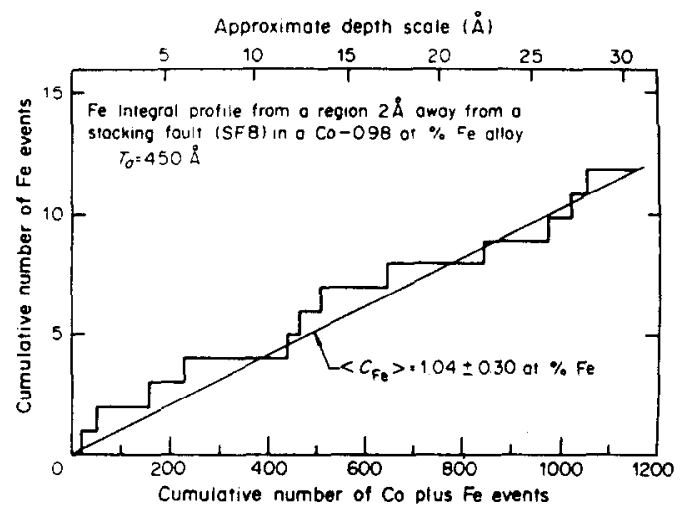

Fig. 20. The $\mathrm{Fe}$ integral profile for a region $2 \AA$ away from a stacking fault (SF8): $\left\langle c_{\mathrm{Fe}}\right\rangle=1.04 \pm 0.30$ at. $\% \mathrm{Fe}$.

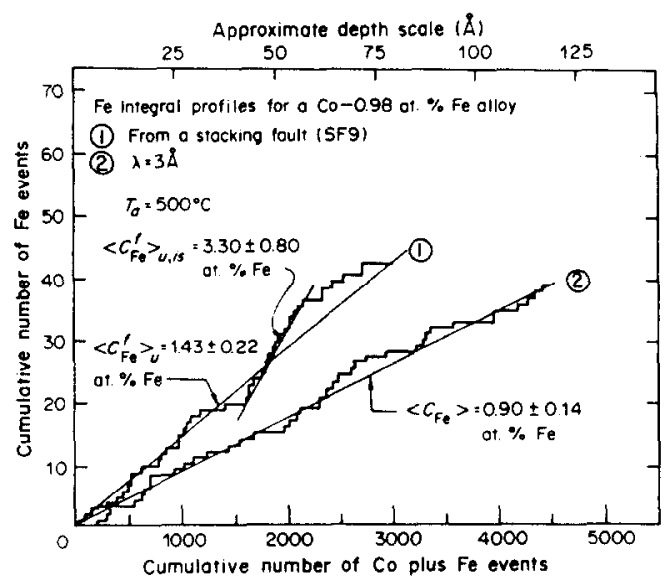

Fig. 21. The Fe integral profiles for: (1) a cylinder of alloy which contained a stacking fault (SF9) and (2) a region $3 \AA$ away from a stacking fault (SF9)- $\left\langle c_{\mathrm{Fe}}^{f}\right\rangle_{u}=1.43 \pm 0.22$ at. $\% \mathrm{Fe}$ and $\left\langle c_{\mathrm{Fe}}\right\rangle=0.90 \pm 0.14 \mathrm{at} \% \mathrm{Fe}$. Note the presence of a local solute fluctuation in (1); $\left\langle c_{\mathrm{Fe}}^{\prime}\right\rangle_{u, i s}=3.30 \pm 0.80$ at $\% \mathrm{Fe}$. This specimen had been annealed at $T_{a}=500^{\circ} \mathrm{C}$ for 14 days. 


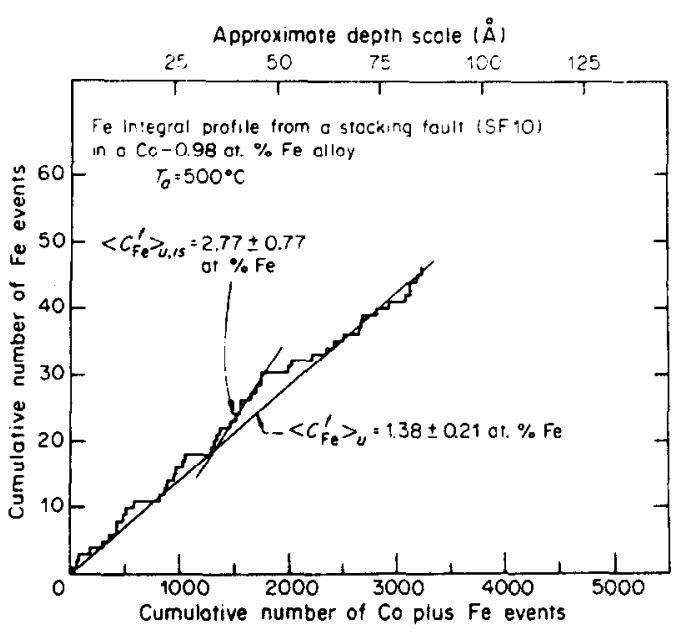

Fig. 22. The Fe integral profile for a cylinder of alloy which contained a stacking fault (SF10)- $\left\langle c_{F_{e}}^{f}\right\rangle_{\psi}=1.38 \pm 0.21$ at. $\% \mathrm{Fe}$. Note the presence of a local solute fluctuation; $\left\langle c_{\mathrm{Fe}}^{f}\right\rangle_{\alpha, i s} 2.77 \pm 0.77$ at. $\%$ Fe. The specimen had been annealed at $T_{a}=500^{\circ} \mathrm{C}$ for 14 days.

and 1.2 , respectively, and $\left\langle c_{\mathrm{Fe}}^{\prime}\right\rangle^{*}$ is greater than $\left\langle c_{\mathrm{Fe}}\right\rangle$ by factors of 10,6 and 4 clearly indicates that $\mathrm{Fe}$ atoms segregate to stacking faults in the Co-0.98 at.\% $\mathrm{Fe}$ alloy.

The experimental $\mathrm{Fe}$ concentration values for $i=2$ or $3 \AA$ indicate that the. Fe concentration profile falls off very rapidly with distance from the plane of the fault. This result in combination with theoretical calculations $[25,26]$ suggests that $F e$ segregation is also most likely confined to the plane of the fault (see Part II).

The presence of large local Fe fluctuations in the integral profiles for $T_{a}=500$ and $575^{\circ} \mathrm{C}$ (SF9, SF 10, $\mathrm{SF} 11$ ) in the $\mathrm{Co}-0.98$ at.\% Fe alloy also indicates the presence of Fe-rich regions $(\sim 20 \AA \mathrm{dia})$ in the plane of the stacking fault whose composition differs

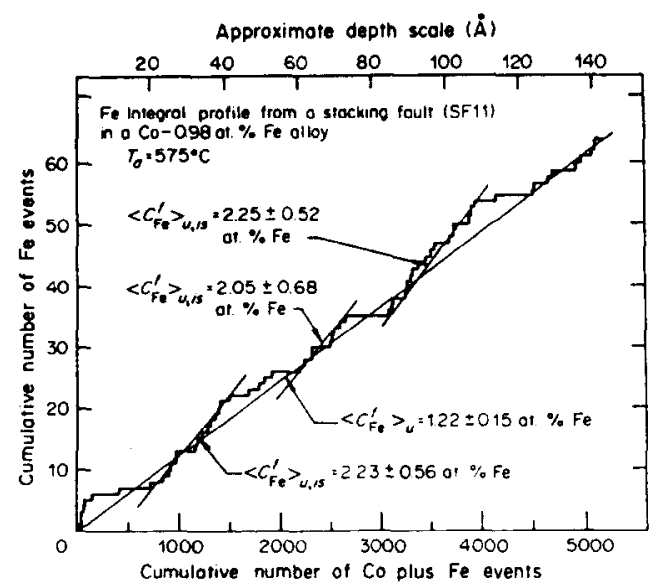

Fig. 23. The Fe integral profile for a cylinder of alloy which contained a stacking lault $(\mathrm{SF} \mid 1):\left\langle\mathrm{a}_{\mathrm{Fi}}^{\prime}\right\rangle_{n}=1.22 \pm 0.15$ at." $\mathrm{Fe}$. Note the presence of local solute fluctuations: $\left\langle\mathrm{c}_{\mathrm{Fe}}^{\prime}\right\rangle_{\mathrm{u}, \mathrm{s}}=2.23 \pm 0.56 .2 .05 \pm 0.68$ and $2.25 \pm 0.52 \mathrm{at} .{ }_{0} \mathrm{Fc}$. This specimen had been amiealed at $T_{4}=5.75 \mathrm{C}$ for 2 days. strongly from $\left\langle c_{\mathrm{Fe}}^{\prime}\right\rangle^{*}$. At $500^{\circ} \mathrm{C}\left\langle c_{\mathrm{re}}\right\rangle_{\text {is }}$ approaches the composition of an ordered two-dimensional phase (see Table 5). These large Fe fluctuations do not exist at $450^{\circ} \mathrm{C}$, but only become significant at the two elevated temperatures. The fact that $\left\langle c_{\mathrm{Fe}}^{\prime}\right\rangle_{i s}$ at these temperatures is greater than $\left\langle c_{\mathrm{Fe}}^{f}\right\rangle^{*}$ at $450^{\circ} \mathrm{C}$ indicates that local equilibrium conditions may not have been achieved at $450^{\circ} \mathrm{C}$.

\section{SUMMARY}

(1) The atom-probe FIM has been used to measure solute atom segregation effects to individual stacking faults in $\mathrm{Co}-0.96$ at. $\% \mathrm{Nb}$ and $\mathrm{Co}-0.98$ at. $\% \mathrm{Fe}$ alloys. These bulk compositions correspond to values within the primary solid solution phase field for the annealing temperatures employed. No evidence of either precipitation on the stacking faults or in the martix was observed in the FIM images.

(2) The temperature dependence of the stacking fault composition has been determined in the range $450-575^{\circ} \mathrm{C}$. The faults were f.c.c in a h.c.p. matrix. Thus, the specimens were not in global thermodynamic equilibrium. However, simple diffusion calculations indicated that the stacking faults were most likely in local thermodynamic equilibrium with the volume surrounding them; i.e. with their solute reservoirs.

(3) The diameter of the analyzed cylinder of alloy was $\sim 30-50 \AA$. It was shown experimentally that solute concentration profile falls off very quickly with distance-within less than $4 \AA$-from the plane of the fault in both alloys. These results in combination with theoretical calculations $[25,26]$ suggest that $\mathrm{Nb}$ or $\mathrm{Fe}$ segregation is most likely confined to the plane of the fault (see Part II).

(4) Very strong solute atom segregation effects to individual stacking faults have been observed in both alloys. After due correction for the matrix contribution to the measured composition, the $\mathrm{Nb}$ concentrations in the stacking faults in a Co-0.96 at.\%

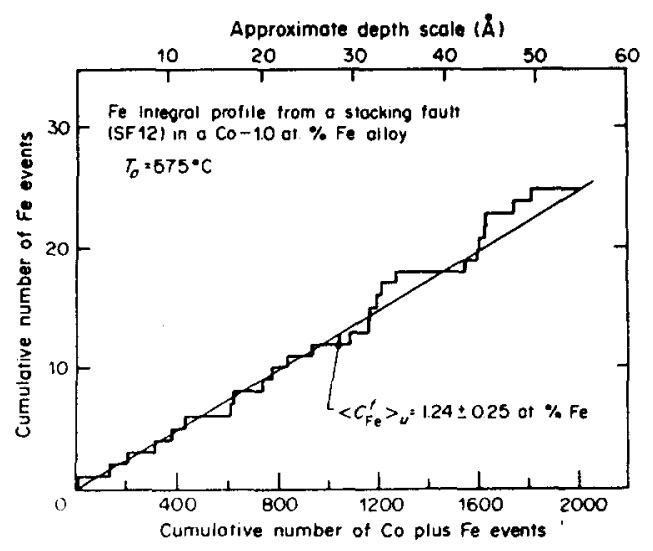

Fig. 24. The Fe integral profile for a cylinder of alloy which conlained a stacking fault (SF 12): $\left\langle c_{\mathrm{re}}^{\prime}\right\rangle_{u}=1.24 \pm 0.25$ at."\% Fe. The specimen had been anrabled at $T_{a}=575^{\circ} \mathrm{C}$ for 2 dilys. 
Nh alloy are greater than the bulk composition by lactors of 30,12 and 7 at the annealing temperatures of 450.525 and $575 \mathrm{C}$.

(5) The corrested Fe concentrations in the stacking liauls in the Co-0.98 at.\% Fe alloy are greater than the bulk composition by factors of 10,6 and 4 at the amnealing temperatures of 450,550 and $575 \mathrm{C}$

(6) Local solute composition fluctuations have been observed in the integral profiles in the Co-0.96 at." Nb alloy at $T_{a}=525$ and $575^{\circ} \mathrm{C}$. These Huctuations are due to solute-rich regions $(\sim 5-20 \AA$ dia) in the plane of the stacking fault, whose concentration differs significantly from the average fault composition. For the Co-0.96 at. $\% \mathrm{Nb}$ alloy the corrected composition of these fluctuations approaches that of a two-dimensional ordered phase. The corrected composition of the stacking faults at $450^{\circ} \mathrm{C}$ is close to that of $\mathrm{Co}_{2} \mathrm{Nb}$. This suggests that in addition to solute-atom segregation, we also have evidence for a disorder-order transformation within the plane of the fault with decreasing temperature.

(7) Local solute composition fluctuations have also been observed in the integral profiles in the $\mathrm{Co}-0.98$ at. $\% \mathrm{Fe}$ alloy at $T_{a}=550$ and $575^{\circ} \mathrm{C}$. The fluctuations are due to solute-rich regions $(\sim 20 \AA$ dia $)$ in the plane of the stacking fault, whose concentration differs significantly from the average fault composition. For the Co-0.98 at.\% Fe alloy the corrected $\mathrm{Fe}$ composition of these fluctuations approaches that of a two-dimensional ordered phase $\left(\mathrm{Co}_{3} \mathrm{Fe}\right)$.

(8) It is shown that even though the composition measured with the atom probe for different stacking faults is approximately the same, some faults are decorated with a large number of "bright spots" along their traces, while others are not decorated at all. This indicates that the mechanism for imaging solute atoms on stacking faults is a function of the crystallographic plane(s) which the fault intersects. It also indicates the danger of using "bright spot" decoration effects to deduce compositional effects [24].

(9) The metallurgy of both $\mathrm{Co}-0.96$ at. $\% \mathrm{Nb}$ and $\mathrm{Co}-0.98$ at. $\% \mathrm{Fe}$ alloys was studied. We have obtained FIM micrographs of these alloys in various states; i.e. pure f.c.c., pure h.c.p. and partially transformed crystals.

(10) The contrast effects produced by stacking faults in the FIM images were enumerated, and a field-evaporation sequence through one pole of an FIM specimen containing two closely-spaced stacking faults- $\sim 20 \AA$ apart-was presented.

(11) It was not found possible to distinguish among the different topologically possible types of stacking faults in the experimental FIM images.

Acknowledgements - This work has been supported by the National Science Foundation through the Materials Science Center at Cornell University. The support of the U.S. Department of Energy is acknowledged for certain technical facilities. We wish to thank Mr Robert Whitmarsh for enthusiastic technical assistance in all phases of the experimental program. Professor J. M. Blakely for many illu- minating discussions on the analogous subject of surface segregation. Prolessor M. E. Fisher and Dr D. Huse for a discussion on the subject of solid-state fluctuations and Professor 11. II. Johnson for enthusiastic encouragement

\section{REFERENCES}

1. W. C. Johnson and J. M. Blakely (editors). Interfacial Segregation. Am. Soc Metals, Metals Park, OH (1979).

2. H. Suzuki, Sei. Rep. Rex. Inst. Tohoku Unir. A 4, 452 (1952).

3. H. Suzuki, J. Phys Soc. Japan 17, 322 (1962).

4. T. Ericson, Acta metall. 14, 853 (1966); A. Korner and H. P. Karnthalcr, Phil. Mag. A 48, 469 (1983).

5. T. C. Tisone, Acta metall. 21, 229 (1973).

6. A. Wagner, T. M. Hall and D. N. Seidman, Rev. scient. Instrum. 46, 1032 (1975).

7. T. M. Hall, A. Wagner, A. S. Berger and D. N. Seidman, Scripta metalt. 10, 485 (1976).

8. T. M. Hatl, A. Wagner and D. N. Seidman. J. Phys. E Sci. Instrum. 10, 884 (1977).

9. A. Wagner, T. M. Hall and D. N. Seidman. J. nucl. Mater. 69, \& 70, 413 (1978).

10. R. Herschitz and D. N. Seidman, Scripta metall. 16, 849 (1982)

II. O. S. Edwards and H. Lipson, Proc. R. Soc. A 180, 268 (1942).

12. C. R. Houska, B. L. Averbach and M. Cohen, Acta metall. 8, 81 (1960).

13. D. Creagh, S. G. Bailey and G. Y. H. Wilson, Phil. Mag. 32, 405 (1975).

14. S. Mahajan, D. Brasen and T. Wakiyama, Metall. Trans. A 9A, 1817 (1978).

15. F. C. Frank, Phil. Mag. 42, 1014 (1951).

16. W. T. Read, Dislocations in Crystals, p. 94. McGrawHill, New York (1953).

17. L. Kaufman, in Phase Stability in Metals and Alloys (edited by P. S. Rudman, J. Stringer and R. I. Jaffe), p. 128. McGraw-Hill, New York (1967).

18. J. P. Hirth and 3. Lothe, Theory of Dislocations, pp. 334-336. McGraw-Hill, New York (1968).

19. M. Hansen and K. Anderko, Constitution of Binary Alloys, pp. 472-484. McGraw-Hill, New York (1958).

20. R. Herschitz and D. N. Seidman, Surf. Sci. 130, 63 (1983).

21. H. M. Otte and A. G. Crocker, Physica status solidi 9. 441 (1965)

22. R. Herschitz and D. N. Seidman, Acta metall. 33, 1565 (1985).

23. A. T. Macrander, M. Yamamoto, D. N. Seidman and S. S. Brenner, Rev. scient. Instrum. 54, 1077 (1983).

24. P. R. Howell, D. E. Fleet, A. Hildon and B. Ralph, J. Microsc. 107, 155 (1976).

25. J. P. Simon, A. M. Papon and P. Guyot, Phil. Mag. B. 44, 69 (1981).

26. F. L. Williams and D. Nason, Surf. Sci. 45, 377 (1974).

27. M. Badia and A. Vignes, Acta metall. 17, 177 (1969).

28. P. M. Morse and H. Feshbach, Methods of Theoretical Physics, pp. 434-435, McGraw-Hill, New York, (1953).

29. D. G. Brandon, J. Sci. Instrum. 43, 708 (1966).

30. J. Amano, A. Wagner and D. N. Seidman, Phil. Mag. A 44, 199 (1981).

\section{APPENDIX A}

On the subject of solute atom equilibrium and redistribution during a quench

The root-mean-square diffusion distance $\left(x^{2}\right)^{1 / 2}$ was estimated from the equation

$$
\left(x^{3}\right)^{1 / 2}=(6 D t)^{1 / 2}
$$


where $D$ is the tracer diffusion coefficient of $\mathrm{Fe}$ in $\mathrm{Co}$ and $t$ is the annealing time.

The expression for $D$ is given by

$$
D=D_{0} \exp \left(-\frac{Q}{k_{B} T}\right)
$$

where $D_{0}$ is the pre-exponential factor, $Q$ is the activation energy for tracer diffusion, $k_{B}$ is Boltzmann's constant and $T$ is the temperature. The values of $D_{0}$ and $Q$ for $\mathrm{Fe}$ in Co are equal to $0.11 \mathrm{~cm}^{2} \mathrm{~s}^{-1}$ and $2.63 \mathrm{eV}$ atom ${ }^{-1}$ [27]. In the absence of diffusion data on the $\mathrm{Co}(\mathrm{Nb})$ system we used the tracer diffusivity of $\mathrm{Fe}$ in $\mathrm{Co}$ to estimate $\left(x^{2}\right)^{1 / 2}$ of $\mathrm{Nb}$ in $\mathrm{Co}$.

We now present a simple qualitative argument that justifies the use of diffusion data for a $\mathrm{Co}(\mathrm{Fe})$ alloy for the $\mathrm{Co}(\mathrm{Nb})$ system. When diffusion occurs by a vacancy mechanism-it is accepted that this mechanism operates in a number of f.c.c. and h.c.p. metals-the diffusion coefficient is determined by the product of the probability that a given neighboring site is vacant times the frequency with which an atom jumps into the vacant neighboring site. The atomic volumes of $\mathrm{Co}$ and $\mathrm{Fe}$ are approximately the same, whereas the atomic volume of $\mathrm{Nb}$ is $\sim 62 \%$ greater than of $\mathrm{Co}$-as a result large strains are produced in the matrix of $\mathrm{Co}(\mathrm{Nb})$ alloy-and hence vacancies will tend to be attracted to $\mathrm{Nb}$ atoms. This, in turn, may lead to faster diffusion of $\mathrm{Nb}$ in a $\mathrm{Co}$ matrix, compared to $\mathrm{Fe}$ diffusion in $\mathrm{Co}$, due to an enhanced vacancy concentration in the $\mathrm{Co}(\mathrm{Nb})$ alloy. And therefore the values given for $\left(x^{2}\right)^{1 / 2}$ are lower bounds for the Co(Nb) system. This is consistent with our suggestion that the $\mathrm{Fe}$ segregation effect at $450^{\circ} \mathrm{C}$ may not have achieved local equilibrium.

The integrated number of jumps $\left(n_{j}\right)$ during a quench was estimated by first evaluating the effective value of $\mathrm{Dt}$ during that period, i.e.

$$
\overline{D t}=\int_{0}^{t} D(t) \mathrm{d} t
$$

where the limits on the integral cover the quench period. The diffusion coefficient $D(l)$ is equal to

$$
D(t)=D_{0} \exp \left[-\frac{Q}{k_{B} T(t)}\right]
$$

where $T(t)$ is the quench rate.

We assumed a linear quench rate, so that

$$
T(t)=T_{a}-\alpha t
$$

wherc $T_{a}$ is the annealing temperature and $\alpha$ is the quench rate constant. By combining equations (A3), (A4) and (A5)

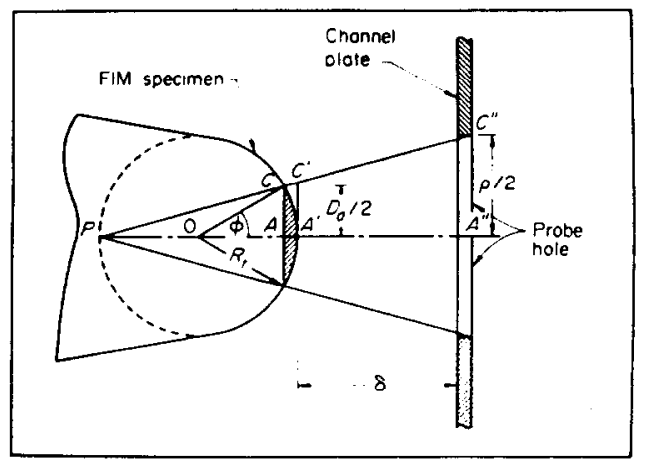

Fig. Al. A schematic illustration of the FIM specimen and its relationship to the image intensilication system. See Appendix B for the derivation of the expression used in evaluatling $1 D$. we obtain the following expression

$$
\overline{D t}=-\frac{D_{0}}{\alpha} \int_{T_{u}}^{T_{1}} \exp \left[-\frac{Q}{k_{b} T(t)}\right] \mathrm{d} T
$$

where $T_{f}$ is the final temperature. Since quenching was done into iced water, $T_{f}=273 \mathrm{~K}$. io evaluate the above integral we let $y=Q / k_{B} T(t)$, hence it becomes

$$
\overline{D t}=\frac{D_{0} Q}{\alpha k_{B}} \int_{y}^{\infty} \frac{\exp (-y)}{y^{2}} \mathrm{~d} y \text {. }
$$

Integrating equation (A7) by parts we obtain

$$
\overline{D t}=\left(\frac{D_{0} Q}{\alpha k_{B}}-\frac{\mathrm{e}^{-y}}{y}+\int_{y}^{x} \frac{\mathrm{e}^{-y}}{y} \mathrm{~d} y\right)
$$

where the integral on the right-hand size is known as $-E i(-y)$ and is given by [28]

$$
\begin{aligned}
-E i(-y)=\int_{y}^{\infty} \frac{\mathrm{e}^{-y} \mathrm{~d} y}{y} \approx \frac{\mathrm{e}^{-y}}{y} \times & \\
& {\left[1-\frac{1}{y}+\frac{2 !}{y^{2}}+\ldots+\frac{(-1)^{n} n !}{y^{n}}\right] . }
\end{aligned}
$$

By using the first two terms of the solution, we obtained

$$
\overline{D t}=\underset{\alpha Q}{D_{0} T_{a}^{2} k_{B}} \exp \left(-\frac{Q}{k_{B} T_{u}}\right)
$$

The numerical answer is essentially the same if one uses 36 terms instead of just two terms. We have estimated an upper limit to the effective value of $\left(x^{2}\right)^{1 / 2}$ by setting $\alpha=10 \mathrm{~K}^{-1}$. This value is less than $1 \AA$, indicating that there was no significant redistribution of solute atoms during a quench. Thus the solute distributions we measured correspond to the distributions characteristic of $T_{a}$.

\section{APPENDIX B}

\section{Quantitative determination of $A_{p}$ and $D_{a}$}

Three different methods were employed to determine the values of the probed area $A_{p}$ and $D_{a}$. In the first method the FIM image is assumed to be a stereographic projection-see Fig. Al; for small values of the angle $\phi$ about the center of the image this is an excellent approximation [29]. The FIM tip is taken to be hemispherical in shape.

The value of $A_{p}$ corresponds to the surface area of a spherical cap (shown cross-hatched in Fig. Al) and is equal to

$$
A_{p}=A_{\text {cap }}=2 \pi R_{t}\left(A A^{\prime}\right)
$$

where $A A^{\prime}=R,(1-\cos \phi)$; therefore

$$
A_{p}=2 \pi R_{i}^{2}(1-\cos \phi) \text {. }
$$

Thus, in order to estimate $A_{p}$ it is necessary to determine the value of $\phi$. From the similar triangles $\triangle P A C$ and $\triangle P A^{\prime} C^{\prime}$ we have,

$$
\frac{A C}{A^{\prime} C^{\prime}}=\frac{P A}{P A^{\prime}}
$$

where $P A=R_{1}(1+\cos \phi), P A^{\prime}=2 R$, and $A C=R_{t} \sin \phi$, and hence

$$
A^{\prime} C^{\prime}=\frac{2 R_{t} \sin \phi}{1+\cos \phi} .
$$

From similar triangles $\triangle P A^{\prime \prime} C^{\prime \prime}$ and $\triangle P A^{\prime} C^{\prime \prime}$ we have

$$
\begin{aligned}
& A^{\prime \prime} C^{\prime \prime}=P A^{\prime \prime} \\
& A^{\prime} C^{\prime}=P A^{\prime}
\end{aligned}
$$

where $P A^{\prime \prime}=2 R_{t}+\delta$, and $A^{\prime \prime} C^{\prime \prime}=\rho / 2$. thus

$$
A^{\prime} C^{\prime \prime}=\begin{gathered}
R_{t} p \\
2 R_{t}+\delta
\end{gathered}
$$


Finally, from equations (B4) and (B6) we ohtaned the following relation for $\phi$

$$
\tan \frac{\phi}{2}=\frac{p i 2}{2 R_{1}+\delta}
$$

or

$$
\phi=2 \arctan \left(\begin{array}{c}
p / 2 \\
2 R+\delta
\end{array}\right)
$$

By substituting equation (B8) into equation (B2) wc obtained the final expression for $A_{p}$,

$$
A_{n}=2 \pi R ;\left\{1-\cos \left[\arctan \left(\frac{\rho / 2}{2 R_{i}+\dot{b}}\right)\right]\right\} \text {. }
$$

The value of $D_{a}$ at small $\phi$ simply corresponds to $2 R$ $\phi$ and is equal to

$$
D_{a}=4 R_{f} \arctan \left(\frac{\rho / 2}{2 R_{i}+\delta}\right) .
$$

Since $R$, is always much less than $\delta$ equations (B9) and (Bi0) arc given to a high degrec of accuracy by

$$
A_{p}=2 \pi R_{i}^{2}\left\{1-\cos \left[2 \arctan \left(\frac{\rho}{2 \delta}\right)\right]\right\}
$$

and

$$
D_{a}=4 R_{t} \arctan \left(\frac{\rho}{2 \delta}\right)
$$

The second method is also based on geometrical considerations; it does not, however, require a knowledge of $\delta$. Figure A2 is a schematic diagram showing crosssectional and top views of the FIM specimen. The diameter of the probed area is given by

$$
D_{a}=r_{n}+r_{x},
$$

where $r_{n}$ is the radius of the last ledge which is covered by the probe-hole and $r_{x}$ is the distance from the central axis of the tip to the closest edge of the probe hole. It can be shown that

$$
r_{n} \cong 2 R_{r} d_{h k 1} n \text {. }
$$

The quantity $r_{x}$ is deduced from the proportionality relationship

$$
r_{x}=r_{1} \frac{R_{x}}{R_{1}}
$$

where $r_{1}$ is the radius of the topmost ledge, $R_{1}$ is the radius of the topmost ledge as measured on the FIM micrograph and $R_{x}$ is the distance from the central axis of the tip to the closest edge of the probe-hole, also as measured on the FIM micrograph.

By substituting equations (B14) and (B15) into equation (B!3) we obtain

$$
D_{a}=\left(2 R_{t} d_{b k_{1}} n+r_{1} \frac{R_{s}}{R_{1}}\right)
$$

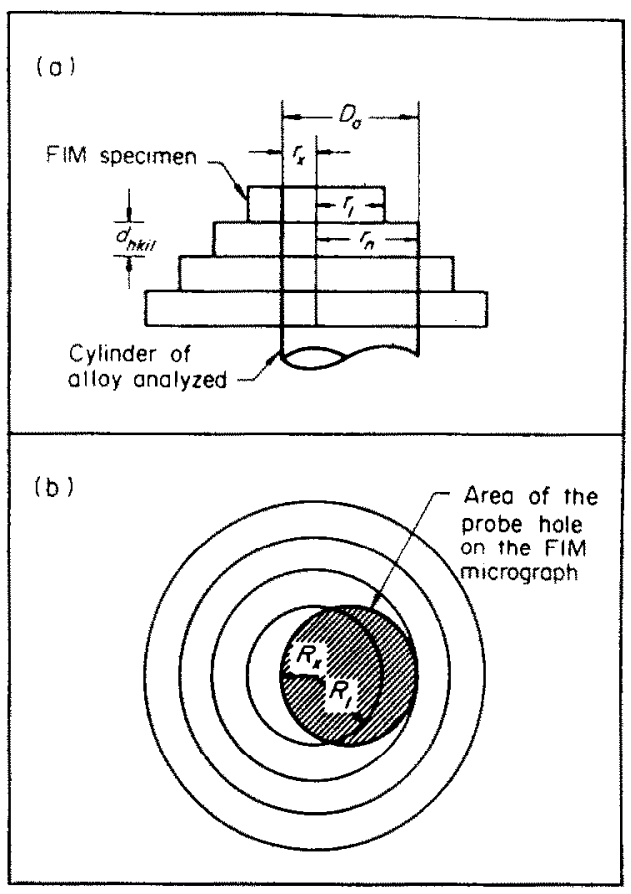

Fig. A2. A schematic diagram showing the cross-sectional and top views of the FIM specimen. It illustrates the relationship between the physical dimensions of the FIM tip to $D_{a}$.

This expression was derived under the assumption that the probe hole is centered about the central axis of the tip.

In case the probe-hole is positioned to one side of the central axis, then

$$
D_{a}=r_{n}-r_{x}
$$

Thus, a completely general expression for $D_{a}$ is given by

$$
D_{a}=\left(2 R_{1} d_{h+1} n \pm r_{1} \frac{R_{x}}{R_{1}}\right) \text {. }
$$

The third method involves counting the number of atoms in each plane field evaporated and is described in great detail in [30]. This method can only be used when the trace of a stacking fault passes through the center of the plane being analyzed. We have compared these methods and found that the calculated diameters of the cyclinder analyzed are the same to within less than $\sim 15 \%$.

The values of $D_{n}$ reported in this paper are the average values calculated by the first two methods. 